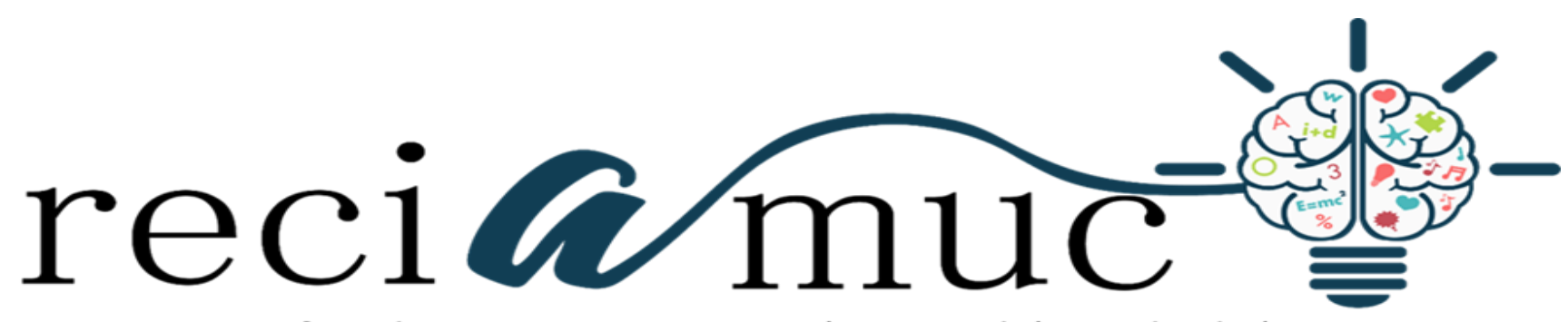

Revista cientifica de investigación actualización del mundo de las ciencias

Jorge Aníbal Guilcaso Romero a; José David Ronquillo Cando b; Raúl Humberto

$$
\text { Montaluisa Pulloquinga }{ }^{c}
$$

Crisis económica política y social del Ecuador periodo 1998 hasta parte del primer semestre del 2018

Economic and political crisis in Ecuador from 1998 to the first half of 2018

Revista Científica de Investigación actualización del mundo de las Ciencias. Vol. 3 núm., 1, enero, ISSN: 2588-0748, 2018, pp. 517-569

DOI: $10.26820 /$ reciamuc/3.(1).enero.2019.517-569

URL: $\underline{\text { http://reciamuc.com/index.php/RECIAMUC/article/view/247 }}$

Código UNESCO: 59 Ciencia Política

Tipo de Investigación: Artículo de Revisión

\author{
Editorial Saberes del Conocimiento
}

Recibido: 10/12/2018

Aceptado: 20/01/2019

Publicado: 30/01/2019

Correspondencia: jorge.guilcaso@utc.edu.ec

a. Magister en Ciencias de la Educación Mención Planeamiento y Administración Educativa; Licenciado en Ciencias de Educación Profesor de Segunda Enseñanza en la Especialización de Filosofía y Ciencias Socio Económicas; Universidad Técnica de Cotopaxi; jorge.guilcaso@utc.edu.ec

b. Magister en Ciencias de la Educación Mención Planeamiento y Administración Educativa; Ingeniero Agroindustrial; Auditor Interno en Sistemas Integrados de Gestión ISO 9001 2015; ISO 45001 2018; ISO 140012015 ; davidronquilloc@yahoo.es

c. Doctor en Ciencias de la Educación, Mención Administración Educativa; Magister en Educación Superior; Licenciado en Ciencias de la Educación, Profesor de Enseñanza Media en la Especialización de Matemática y Física; Universidad Técnica de Cotopaxi; raul.montaluisa@utc.edu.ec 
Crisis económica política y social del Ecuador periodo 1998 hasta parte del primer semestre del 2018

Vol. 3, núm. 1., (2019)

Jorge Aníbal Guilcaso Romero; José David Ronquillo Cando; Raúl Humberto Montaluisa Pulloquinga

\section{RESUMEN}

La presente investigación tiene como objetivo analizar la crisis económica política y social del Ecuador periodo 1998- 2018, con el fin de conocer las variables macroeconómicas más importantes que afectan la economía del país, como son la inflación, Producto Interno Bruto, Ingresos Fiscales, precio del petróleo, desempleo.

Ecuador, no ha logrado un progreso en esta década, como son: la existencia de elevadas tasas de desempleo y subempleo, la desaceleración de la demanda, el decrecimiento de algunos sectores de la economía, la aún dependencia existente en el sector petrolero y la volatilidad de los precios internacionales del petróleo, así como la pérdida de competitividad de las exportaciones, demostradas en la apreciación del tipo de cambio real. Para lo cual se utilizara el método cualitativo el cual permitirá recolectar información a través de una encuesta previamente estructurada, la cual permitirá conocer la opinión de la ciudadanía, en cuanto a las causas que afectan que la crisis económica del país avance.

Palabras Claves: Crisis; Financiera; Política; Social; Fiscal. 


\title{
Crisis económica política y social del Ecuador periodo 1998 hasta parte del primer semestre del 2018
}

Vol. 3, núm. 1., (2019)

Jorge Aníbal Guilcaso Romero; José David Ronquillo Cando; Raúl Humberto Montaluisa

Pulloquinga

\begin{abstract}
The objective of this research is to analyze the political and social economic crisis of the period 1998- 2018, in order to know the most important macroeconomic variables that affect the economy of the country, such as inflation, Gross Domestic Product, Fiscal Income, price of oil, unemployment.

Ecuador, has not achieved progress in this decade, such as: the existence of high rates of unemployment and underemployment, the slowdown in demand, the decline of some sectors of the economy, the existing dependence on the oil sector and volatility of international oil prices, as well as the loss of competitiveness of exports, demonstrated in the appreciation of the real exchange rate. For which the qualitative method will be used which will allow to collect information through a previously structured survey, which will allow to know the opinion of the citizenship, regarding the causes that affect that the economic crisis of the country advances.
\end{abstract}

Key Words: Crisis; Financial; Politics; Social; Fiscal. 


\section{Crisis económica política y social del Ecuador periodo 1998 hasta parte del primer semestre del 2018}

Vol. 3, núm. 1., (2019)

Jorge Aníbal Guilcaso Romero; José David Ronquillo Cando; Raúl Humberto Montaluisa Pulloquinga

\section{Introducción.}

Durante los ochenta, Ecuador pasó un proceso de ajuste estructural y promoción de exportaciones, lo que le permitió enfrentar la deuda económica de ese entonces, como menciona Cerdas, Jiménez , \& Valverde en su investigación donde presenta que "Los conflictos sociales que se dieron y un ambiente de inestabilidad política en los años 90, el país había liberalizado el tipo de cambio y las tasas de interés, además se disminuyó la protección arancelaria y se abrieron sus mercados, eliminando los subsidios y otras distorsiones en sus precios relativos” (pág. 2).

A finales de los años 90, la situación ecuatoriana empeoró por diversos factores, entre ellos el fenómeno del Niño de 1998 y la caída del precio del petróleo en el mercado mundial. En 1998 el precio llego a valores cercanos a los USD 7 por barril, cuando estuvo presupuestado en USD 16 para dicho año. Se estima que si el promedio anual bordea los USD 16, la perdida para el fisco representaría unos 400 millones de dólares, pero si este precio promedio se sitúa en unos USD 8, la perdida sería de unos 640 millones de dólares (Acosta , 1998).

Entre 1999 y el año 2000 el sistema financiero se vio afectado por la peor crisis de la historia, en el gobierno de Jamil Mahuad decretó el congelamiento de depósitos durante un año y la medida llegando acompañada de un paquetazo económico, con la venia del Congreso Nacional, de mayoría socialcristiana. Después de 18 años, las miles de víctimas relatan como esa decisión acabo con la economía de sus hogares, provocando, suicidios, por el cierre de más de la mitad de los bancos del país, repercutiendo en la estabilidad económica. Esta situación ha repercutido en un elevado costo social, en términos de incremento en la desigualdad y persistencia de la pobreza y desempleo (Espinoza, 2005). 


\section{Crisis económica política y social del Ecuador periodo 1998 hasta parte del}

primer semestre del 2018

Vol. 3, núm. 1., (2019)

Jorge Aníbal Guilcaso Romero; José David Ronquillo Cando; Raúl Humberto Montaluisa Pulloquinga

En este contexto, los derrocamientos presidenciales de Abdalá Bucaram en 1997, de Jamil Mahuad en enero de 2000 y de Lucio Gutiérrez en abril de 2005, pueden ser leídos, en parte, "como un resultado de las masivas movilizaciones de diversos sectores opuestos a las reformas de ajuste estructural y por la profunda crisis política que ha venido agravándose en el país. Esta inestabilidad política hace que en la década de los noventa Ecuador haya tenido cinco presidentes, una destitución vicepresidencial (1995), y dos derrocamientos presidenciales (1997 y 2000)" (Muñoz , 2006, pág. 5).

La crisis política se presenta, debido a la inestabilidad, y desorden político, hechos que han marcado de gran forma la vida del país, sobre todo de los ecuatorianos a lo largo de la historia, como lo indican varios estudios realizados sobre el tema de estudio, dándonos cuenta que la crisis política es uno de los puntos de partida para la crisis económica y social, debido a que si el país se encuentra en conflicto político, se verá inmiscuido en conflictos económicos y sociales, Ecuador está sumergido en un enredo político-jurídico que preocupa a la comunidad internacional y mantiene a la expectativa a los ecuatorianos por las decisiones política.

Ante los acontecimientos ocurridos en el país se pretende analizar la crisis económica política y social del Ecuador que ha vivido y vive en el transcurso del tiempo, los que permitirá conocer y analizar los diversos factores que generaron la crisis en un determinado momento, ya que en la actualidad el país está enfrentando a una crisis macroeconómica, a consecuencia de la combinación del desastre natural, crisis de la banca, doble crisis de divisas, paralización de producción en algunos sectores económicos, suspensión de servicios públicos en educación y salud. Según (León , Ponce, Troya , Velazco , \& Brborich, 2000), el Estado ecuatoriano está al 
Crisis económica política y social del Ecuador periodo 1998 hasta parte del primer semestre del 2018

Vol. 3, núm. 1., (2019)

Jorge Aníbal Guilcaso Romero; José David Ronquillo Cando; Raúl Humberto Montaluisa Pulloquinga

borde de la bancarrota, arrastra una enorme deuda pública y la crisis económica oscila entre los 58.000 millones al 2017 junto con la caída de los precios internacionales del petróleo hacen improbable un aumento de la recaudación fiscal. A ello se suma una parálisis institucional grave, con un presidente aislado frente a un Parlamento unificado en su contra. Choques con la Justicia, una dirigencia política sumida en el marasmo y un estado de rebelión popular indígena que se expresa en movilizaciones con toma de edificios.

Ecuador, afronta problemas económicos, con una deuda interna y externa, sumada a otras obligaciones, asciende a unos 58.979 millones de dólares, equivalente a un $57 \%$ de su Producto Interno Bruto (PIB).

A Diciembre del 2017 la deuda asciende a 48.000 millones de dólares entre interna y externa. Y si consideramos las otras obligaciones estamos hablando de cerca de 10.000 millones de dólares" adicionales, declaró el ministro de Finanzas, Richard Martínez, en una entrevista con un medio televisivo.

La cartera precisó en su más reciente reporte de deuda pública que hasta abril del 2018 la deuda externa era de 34.492 millones de dólares, mientras que la interna alcanzaba los 14.355 millones de dólares.

El informe incluye otros pasivos, entre ellos la venta anticipadas de petróleo ecuatoriano, por un monto de 10.132 millones de dólares. 


\section{Crisis económica política y social del Ecuador periodo 1998 hasta parte del}

primer semestre del 2018

Vol. 3, núm. 1., (2019)

Jorge Aníbal Guilcaso Romero; José David Ronquillo Cando; Raúl Humberto Montaluisa

Pulloquinga

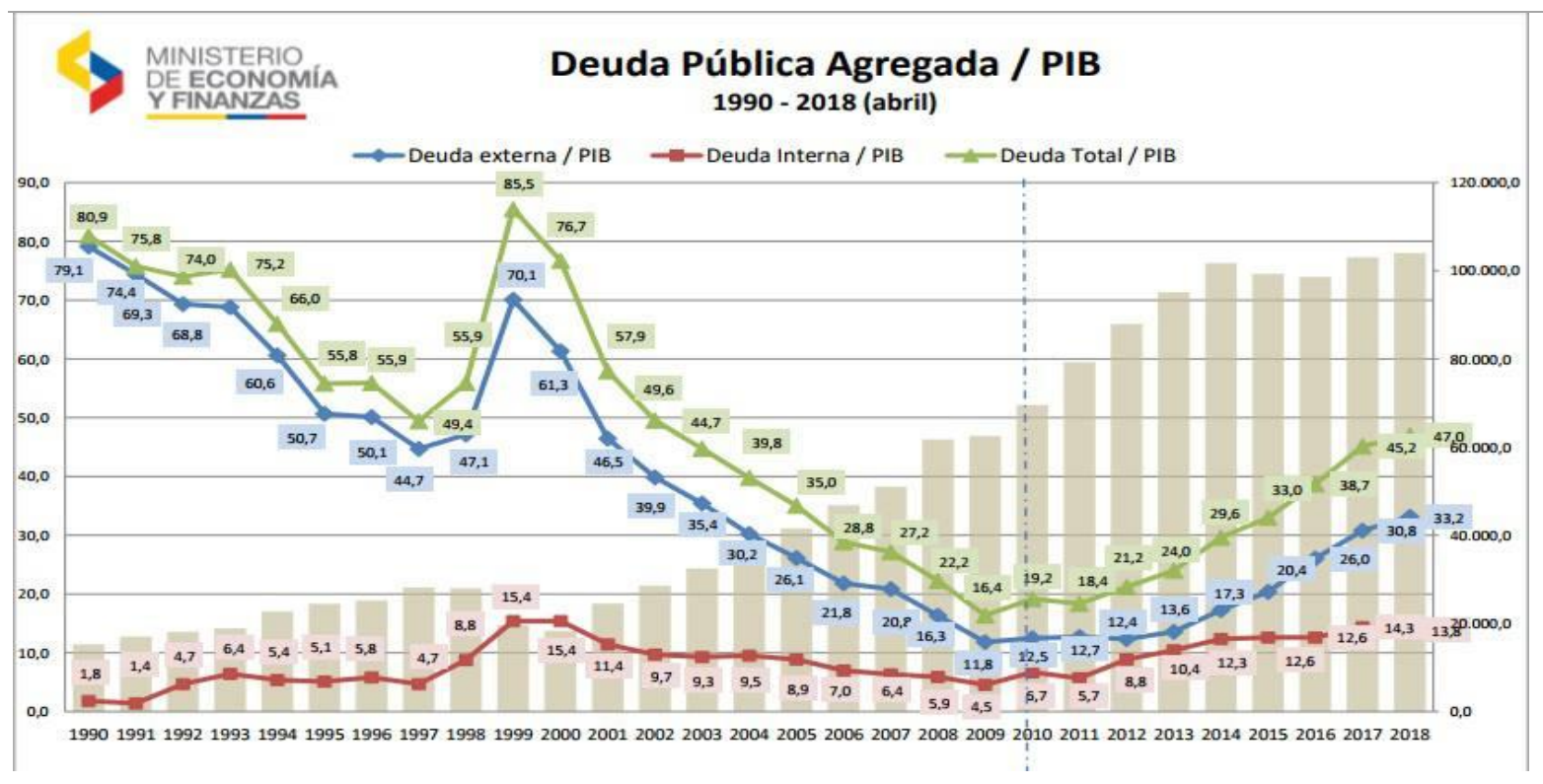

\section{Gráfico 1 Deuda Pública}

Fuente: Banco Central del Ecuador (2017)

Elaborado por: Los Autores

Análisis de las causas de la crisis económica, políticas y sociales en el ecuador

Con lo mencionado en apartados anteriores se puede ver que la economía y sociedad ecuatoriana ha venido atravesando una crisis estructural; debido que "Las fuerzas que originan están ancladas en el pasado y obedecen a razones intrínsecas al propio modelo de funcionamiento de la sociedad." Según Aguilera (2015), indica características evidentes de un retraso económico con relación a otras regiones del mundo, de forma que no se ha podido incorporar adelantos técnicos, procesos de bienes y productos, así como también tampoco se han alterado los tradicionales patrones de dependencia financiera y tecnológica del exterior. 
Crisis económica política y social del Ecuador periodo 1998 hasta parte del primer semestre del 2018

Vol. 3, núm. 1., (2019)

Jorge Aníbal Guilcaso Romero; José David Ronquillo Cando; Raúl Humberto Montaluisa Pulloquinga

La crisis económica, política y social ayuda a graficar a través de los siguientes indicadores:

\section{Crecimiento irregular del PIB}

El crecimiento reducido y desigual del PIB real, con caídas permanentes de ingreso percápita en los últimos años, ha sido una constante perniciosa en el panorama económico de la última década lo cual se traduce en una baja tasa de acumulación y débil desarrollo de las fuerzas productivas. Su crecimiento inferior al de la población ha colocado al producto interno percápita en el mismo nivel de hace 15 años.

Así, mientras en 1988 la variación porcentual anual del PIB era del 10.5\% que correspondía a un PIB percápita de 932 USD, una década después el PIB era de 3.3\% y el PIB percápita de 1679 USD, con variaciones como en 1996, que apenas fue del 2\%, es decir inferior a la tasa de crecimiento poblacional, en comparación con el año 1997 el PIB creció al 3.4\% signo inequívoco de recesión económica, la cual no hemos podido superar hasta la presente fecha como se puede ver en el grafico 1. (Salgado, 2016) 


\section{Crisis económica política y social del Ecuador periodo 1998 hasta parte del}

primer semestre del 2018

Vol. 3, núm. 1., (2019)

Jorge Aníbal Guilcaso Romero; José David Ronquillo Cando; Raúl Humberto Montaluisa

Pulloquinga

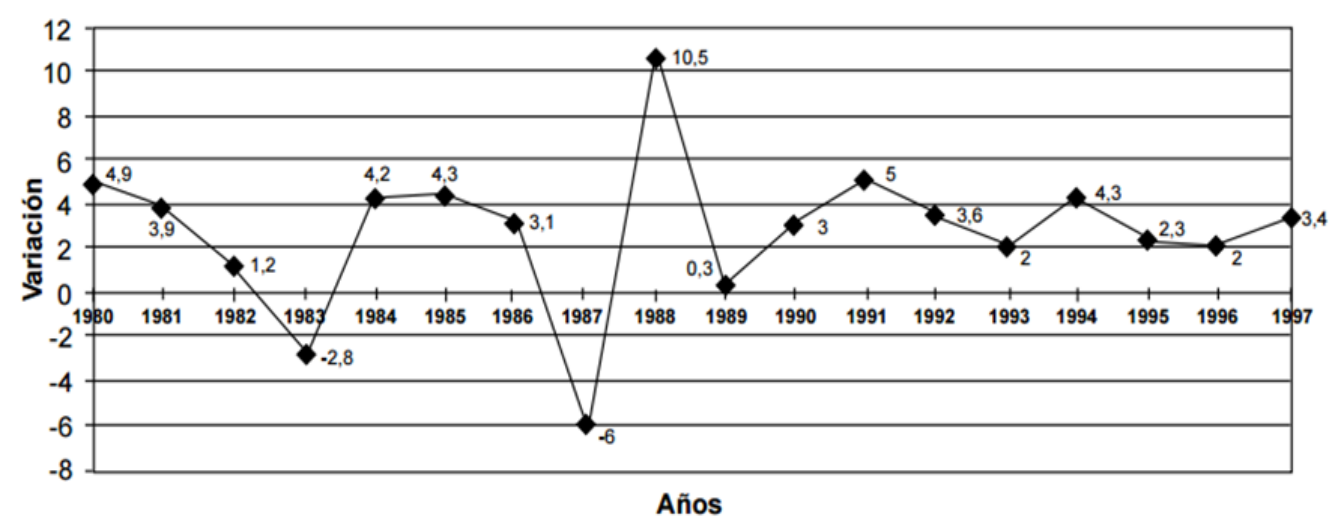

Gráfico 2 Variación del PIB desde 1980 al 1997en el Ecuador

Fuente: (Salgado, 2016), La crisis económicas en el Ecuador y los derechos económicos sociales.

Tabla 1 Evolución del PIB Anual Ecuador de 1999 al 2017

\begin{tabular}{|c|c|}
\hline Ã̃) & $\begin{array}{c}\text { VAR. PIB } \\
(\%)\end{array}$ \\
\hline 2017 & $3 \%$ \\
\hline 2016 & $-1.6 \%$ \\
\hline 2015 & $0.1 \%$ \\
\hline 2014 & $3.8 \%$ \\
\hline 2013 & $4.9 \%$ \\
\hline 2012 & $5.6 \%$ \\
\hline 2011 & $7.9 \%$ \\
\hline 2010 & $3.5 \%$ \\
\hline 2009 & $0.6 \%$ \\
\hline 2008 & $6.4 \%$ \\
\hline 2007 & $2.2 \%$ \\
\hline 2006 & $4.4 \%$ \\
\hline 2005 & $5.3 \%$ \\
\hline 2004 & $8.2 \%$ \\
\hline 2003 & $2.7 \%$ \\
\hline 2002 & $4.1 \%$ \\
\hline
\end{tabular}


Crisis económica política y social del Ecuador periodo 1998 hasta parte del primer semestre del 2018

Vol. 3, núm. 1., (2019)

Jorge Aníbal Guilcaso Romero; José David Ronquillo Cando; Raúl Humberto Montaluisa Pulloquinga

\begin{tabular}{|c|c|}
\hline 2001 & $4.0 \%$ \\
\hline 2000 & $1.1 \%$ \\
\hline 1999 & $-4.7 \%$ \\
\hline
\end{tabular}

Fuente: Banco Central del Ecuador (2017)

Elaborado por: Los Autores

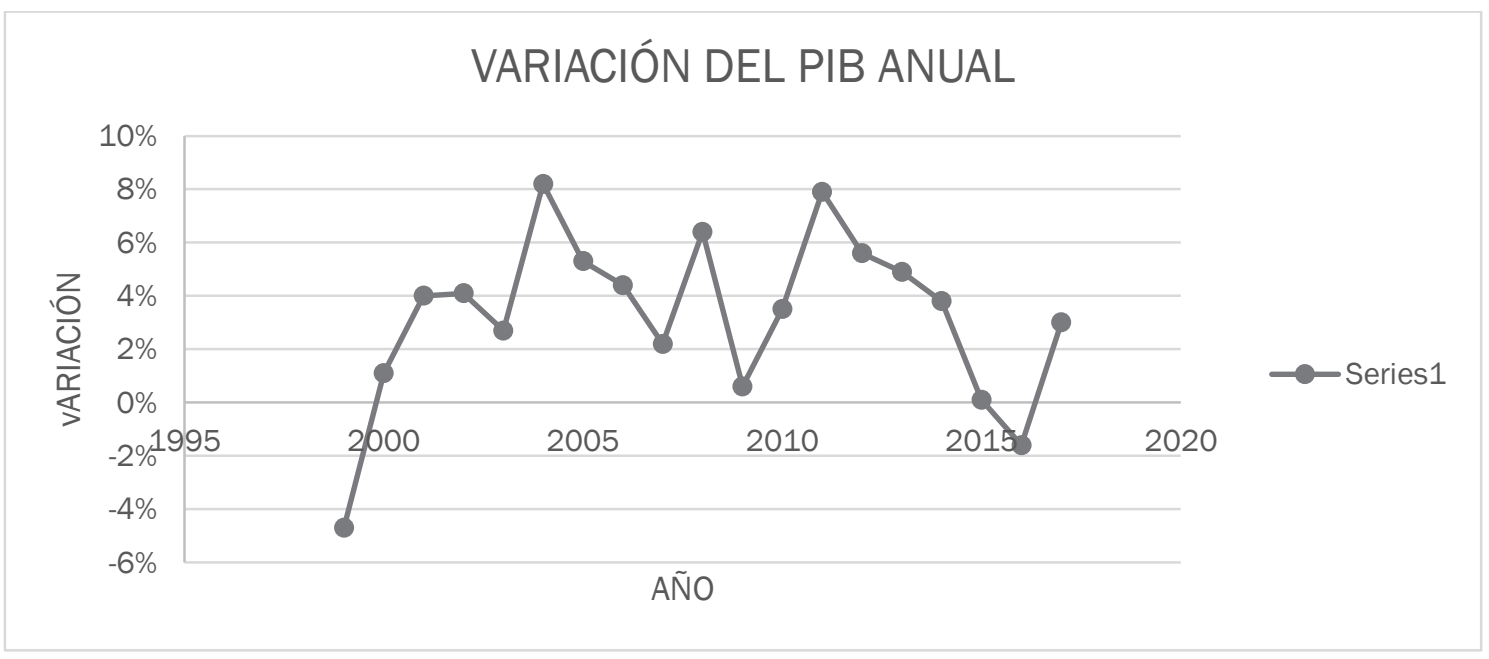

Gráfico 3 Variación del PIB Ecuador de 1999 al 2017

Fuente: Banco Central del Ecuador (2017)

Elaborado por: Los Autores

Como se puede ver en el grafico 2 la evolución del PIB anual en el Ecuador en el transcurso del tiempo en el año 1999 fue de $-4.7 \%$, en el año 2000 el 1.1\%, en el 2001 fue del 4.0\%, en el año 2002 el ecuador tenía un PIB del 4.1\%, en el 2003 tenía un 2.7\%, en el 2004 tenía 8.2\%, en el año 2005 tenía un 5.3\%, en el año 2006 tenía un PIB anual de 4.4\%, en el 2007 estaba con 2.2\%, en el año 2008 tenía un 6.4\%, en el año 2009 tenía $0.6 \%$, el producto interno 


\section{Crisis económica política y social del Ecuador periodo 1998 hasta parte del primer semestre del 2018}

Vol. 3, núm. 1., (2019)

Jorge Aníbal Guilcaso Romero; José David Ronquillo Cando; Raúl Humberto Montaluisa

Pulloquinga

bruto en ecuador en el 2010 presento un incremento del 3.5\% respecto al del 2009, es decir creció en una tasa de 29 décimas más que el 2009 ya que en ese año se tuvo $0.6 \%$, en el año 2011 tuvo un incremento del 7.9\%, en relación al 2012 ya que en este año tuvo un incremento de $3.8 \%$, y $4.9 \%$ en el 2013, en el 2014 tuvo un incremento de 3.8\%, con relación al 2015 ya que en ese año tuvo un incremento del $0.1 \%$, mientras que en el 2016 decreció en $-1.6 \%$ y en el 2017 incremento un $3 \%$.

Según Álvarez (2000), entre las causas de la recesión económica están el creciente e irreductible tamaño del Estado que en la actualidad absorbe una cuantiosa parte de los recurso económicos, aproximadamente el $47 \%$ del PIB, cuyos fondos generalmente se destinan al gasto corriente y muy poco a la inversión. Otra de las causas de esta situación está en la creciente deuda externa que para 1998 ascendió a 15.099 millones de dólares, la misma que comparada con el volumen de exportaciones, el PIB y el crecimiento poblacional le colocan a nuestro país, junto a Brasil, Camerún, Marruecos y Siria como uno de los países severamente endeudados del mundo, Además, los valores que el estado invierte en el pago del servicio de la deuda en los últimos años ha absorbido alrededor del $40 \%$ del presupuesto nacional.

\section{Inflación}

Según Faria \& Sabino (1997), la inflación ocurre cuando todos o casi todos los precios suben, como empujados por una fuerza que actuase sobre su nivel general, y cuando estos aumentos se hacen recurrentes, como si nunca fueran a detenerse. No hay inflación cuando un grupo de bienes o servicios aumenta de precio con relación a los otros, como en el caso de una 


\section{Crisis económica política y social del Ecuador periodo 1998 hasta parte del primer semestre del 2018}

Vol. 3, núm. 1., (2019)

Jorge Aníbal Guilcaso Romero; José David Ronquillo Cando; Raúl Humberto Montaluisa Pulloquinga

mala cosecha que, provocando escasez, hace subir el precio de algunos rubros alimenticios; no acostumbramos a hablar de inflación, tampoco, cuando nos referimos a un aumento generalizado pero que no se sostiene en el tiempo, como en el caso de lo que ocurría en Venezuela hasta mediados de los años setenta. La inflación es algo más general, es una especie de enfermedad de la economía a la que nadie puede escapar porque obliga de hecho a todos los actores económicos, a quienes venden o compran, a los trabajadores y a los empresarios, a subir los precios de lo que venden para no quedarse detrás. Quien no lo hace corre el riesgo de sufrir fuertes pérdidas, de ver reducidos sus ingresos o de hacer quebrar su negocio.

Los índices de inflación registrados en la última década refieren dos periodos de ascenso, esto es, entre 1990 y 1992, en que va del 48,5\% al 54.6\%; y otro, que va desde 1996 en que alcanza $24.4 \%$ hasta la presente en que registra cifras por sobre el $45 \%$. El periodo de descenso se evidencia entre 1993 y 1995, año en que se registra la menor cifra de la década con $22.9 \%$, coincidiendo con una aparente recuperación económica. Actualmente nuestro país mantiene las cifras más altas de inflación de América Latina y el Caribe solo siendo superada por Haití. Entre las causas que expliquen esta galopante inflación está la creciente desvalorización de nuestra moneda frente al dólar, así, mientras en 1988 el dólar se cotizaba en 512 sucres, en 1998 alcanzo 5000 sucres, es decir, un incremento del 1000\% en 10 años.

En el año 2000 la inflación llego al 96\% acorde al cambio de moneda que vivió el país en esa época, mientras que del año 2005 al 2011 tuvo una variación de 1.3\%, y en el año 2012 al 2016 ha sufrido una variación del 2.5\% con relación a los años anteriores. (Acosta \& Serrano, 2016) 


\section{Crisis económica política y social del Ecuador periodo 1998 hasta parte del}

primer semestre del 2018

Vol. 3, núm. 1., (2019)

Jorge Aníbal Guilcaso Romero; José David Ronquillo Cando; Raúl Humberto Montaluisa

Pulloquinga

Tabla 2 Variación Inflacionaria Anual Ecuador de 199 al 2017

\begin{tabular}{|c|c|}
\hline AÑ O & $\begin{array}{c}\text { VAR. INFL. } \\
(\mathbf{\%})\end{array}$ \\
\hline 2017 & $0.7 \%$ \\
\hline 2016 & $2.4 \%$ \\
\hline 2015 & $2.3 \%$ \\
\hline 2014 & $2.70 \%$ \\
\hline 2013 & $2.6 \%$ \\
\hline 2012 & $5.1 \%$ \\
\hline 2011 & $4.5 \%$ \\
\hline 2010 & $3.3 \%$ \\
\hline 2009 & $4.3 \%$ \\
\hline 2008 & $8.3 \%$ \\
\hline 2007 & $2.3 \%$ \\
\hline 2006 & $3.4 \%$ \\
\hline 2005 & $2.1 \%$ \\
\hline 2004 & $2 \%$ \\
\hline 2003 & $7.9 \%$ \\
\hline 2002 & $12.5 \%$ \\
\hline 2001 & $22 \%$ \\
\hline 2000 & $96 \%$ \\
\hline 1999 & $59,9 \%$ \\
\hline \multicolumn{2}{|c}{}
\end{tabular}

Fuente: Banco Central del Ecuador (2017)

Elaborado por: Los Autores 
Crisis económica política y social del Ecuador periodo 1998 hasta parte del primer semestre del 2018

Vol. 3, núm. 1., (2019)

Jorge Aníbal Guilcaso Romero; José David Ronquillo Cando; Raúl Humberto Montaluisa Pulloquinga

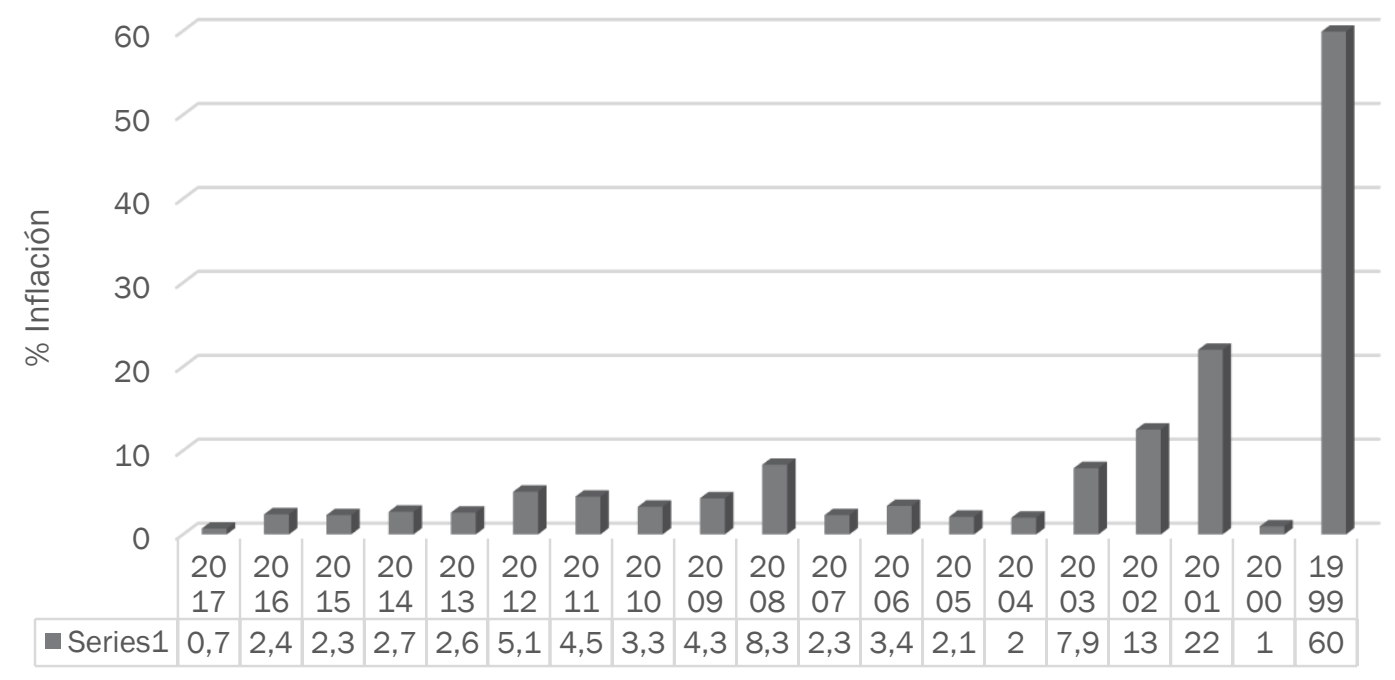

Gráfico 4 Variación Inflacionaria Ecuador de 199 al 2017

Fuente: Index Mundi (2018)

Elaborado por: Los Autores

Con los datos obtenidos anteriormente se pudo concluir que, en junio de 2018, el Índice de Precios al Consumidor (IPC) registró las siguientes variaciones: -0,27\% la inflación mensual; $-0,71 \%$ la anual; y, $-0,19 \%$ la acumulada; para el mismo mes en el 2017 fue de $-0,58 \%$ la inflación mensual; $0,16 \%$ la anual; y, 0,32\% la acumulada prácticamente tres veces y un poco más con respecto a países dolarizados como Panamá. EE. UU. Puerto Rico lo cual quiere decir que somos un país extremadamente caro. Index Mundi (2018)

Hay cuatro variables en la economía que son básicos: el tipo de cambio, la tasa de interés, la inflación y el empleo. Hemos solucionado un problema, el tipo de cambio, pero subsisten los tres restantes", dice el catedrático de la UTE. 


\section{Crisis económica política y social del Ecuador periodo 1998 hasta parte del}

primer semestre del 2018

Vol. 3, núm. 1., (2019)

Jorge Aníbal Guilcaso Romero; José David Ronquillo Cando; Raúl Humberto Montaluisa Pulloquinga

Sin embargo Aulestia, quien fue presidente de la Federación Ecuatoriana de Economistas, considera que el mismo Gobierno no tiene políticas de producción, por lo cual los productores locales actualmente tienen que endeudarse a tasas de interés del 24 por ciento, "sabiendo que su rentabilidad no será más del 20 por ciento".

Otros problemas que ve en el aumento constante de los precios tienen relación con la participación de los intermediarios (según el INEC, éstos encarecen los productos en un 120 por ciento), y con el hecho de que la dolarización estimula las importaciones en desmedro de la producción exportable nacional.

"Se premia a las importaciones porque en el exterior los precios suben en un cinco por ciento, mientras en el país aumentan en un 20 por ciento", expresa.

Otro "error" de los ecuatorianos es no obligar al uso de monedas fraccionarias. "Nos olvidamos que un dólar significa 25 mil sucres; deberíamos obligar su uso". De manera que se está manejando precios similares a Honduras, los precios de algunos productos ecuatorianos son casi iguales a los de Honduras, país centroamericano que tiene como moneda oficial a la Lempira que equivale a 16,20 dólares de los Estados Unidos. (La Hora, 2018)

\section{Desempleo y subempleo}

La crisis económica, política y social afectado a todo el pueblo ecuatoriano, debido a que tiene mayor repercusión en los sectores de mayor vulnerabilidad, por ejemplo la tasa de desempleo del quinto más pobre de los ecuatorianos es más del doble que aquella de toda la población. Pero, además, la crisis ha generado un grupo de nuevos pobres: aquellos que han 
Crisis económica política y social del Ecuador periodo 1998 hasta parte del primer semestre del 2018

Vol. 3, núm. 1., (2019)

Jorge Aníbal Guilcaso Romero; José David Ronquillo Cando; Raúl Humberto Montaluisa Pulloquinga

perdido su empleo regular en el sector formal o que han sufrido una fuerte caída de sus ingresos reales. Durante 1999, las restricciones fiscales han puesto en riesgo la operación de los servicios públicos afectando sobre todo a la población de escasos recursos que depende mayoritariamente de ellos (Larrea \& Sánchez, 2015).

Tabla 3 Evolución de la tasa de desempleo Anual Ecuador de 199 al 2017

\begin{tabular}{|c|c|c|}
\hline AÑ & $\begin{array}{c}\text { VAR. } \\
\text { DESEMPLEO } \\
(\boldsymbol{\%})\end{array}$ & $\begin{array}{c}\text { SUBEMPLEO } \\
(\boldsymbol{\%})\end{array}$ \\
\hline 2017 & $4.6 \%$ & $14 \%$ \\
\hline 2016 & $5.3 \%$ & $19.9 \%$ \\
\hline 2015 & $4.77 \%$ & $14.01 \%$ \\
\hline 2014 & $3.80 \%$ & $12.87 \%$ \\
\hline 2013 & $4.57 \%$ & $48.3 \%$ \\
\hline 2012 & $4.6 \%$ & $46.1 \%$ \\
\hline 2011 & $5.1 \%$ & $48.5 \%$ \\
\hline 2010 & $6.1 \%$ & $47.1 \%$ \\
\hline 2009 & $7.9 \%$ & $46.47 \%$ \\
\hline 2008 & $7.3 \%$ & $48.8 \%$ \\
\hline 2007 & $13 \%$ & $53.7 \%$ \\
\hline 2006 & $10.6 \%$ & $47.1 \%$ \\
\hline 2005 & $9.71 \%$ & $46.6 \%$ \\
\hline 2004 & $9.3 \%$ & $64 \%$ \\
\hline 2003 & $9.2 \%$ & $45.8 \%$ \\
\hline 2002 & $8.8 \%$ & $39.2 \%$ \\
\hline 2001 & $9.5 \%$ & $10.9 \%$ \\
\hline 2000 & $12.3 \%$ & $37.1 \%$ \\
\hline 1999 & $14.4 \%$ & $47 \%$ \\
\hline
\end{tabular}

Fuente: Banco Central del Ecuador (2017)

Elaborado por: Los Autores 


\section{Crisis económica política y social del Ecuador periodo 1998 hasta parte del}

primer semestre del 2018

Vol. 3, núm. 1., (2019)

Jorge Aníbal Guilcaso Romero; José David Ronquillo Cando; Raúl Humberto Montaluisa

Pulloquinga

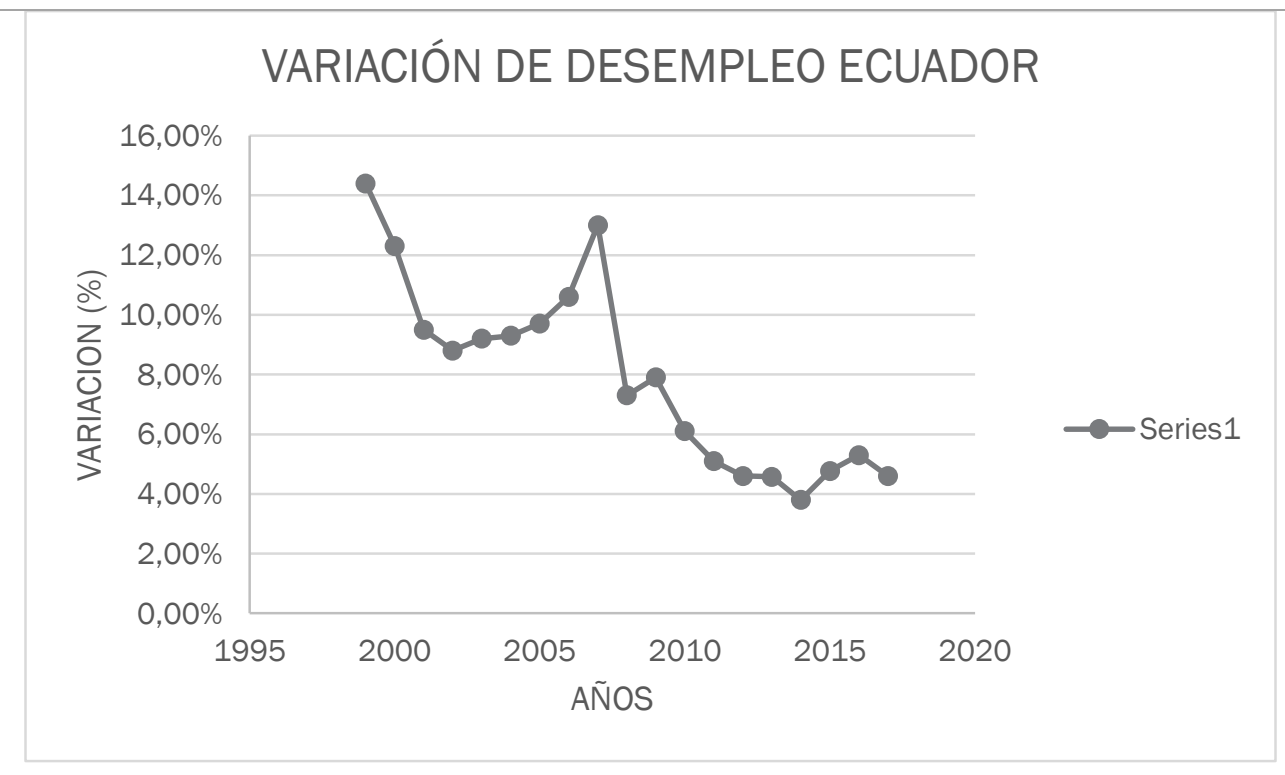

Gráfico 5 Variación de la tasa de desempleo en el Ecuador de 1999 al 2017

Fuente: Banco Central del Ecuador (2017)

Elaborado por: Los Autores 
Crisis económica política y social del Ecuador periodo 1998 hasta parte del primer semestre del 2018

Vol. 3, núm. 1., (2019)

Jorge Aníbal Guilcaso Romero; José David Ronquillo Cando; Raúl Humberto Montaluisa Pulloquinga

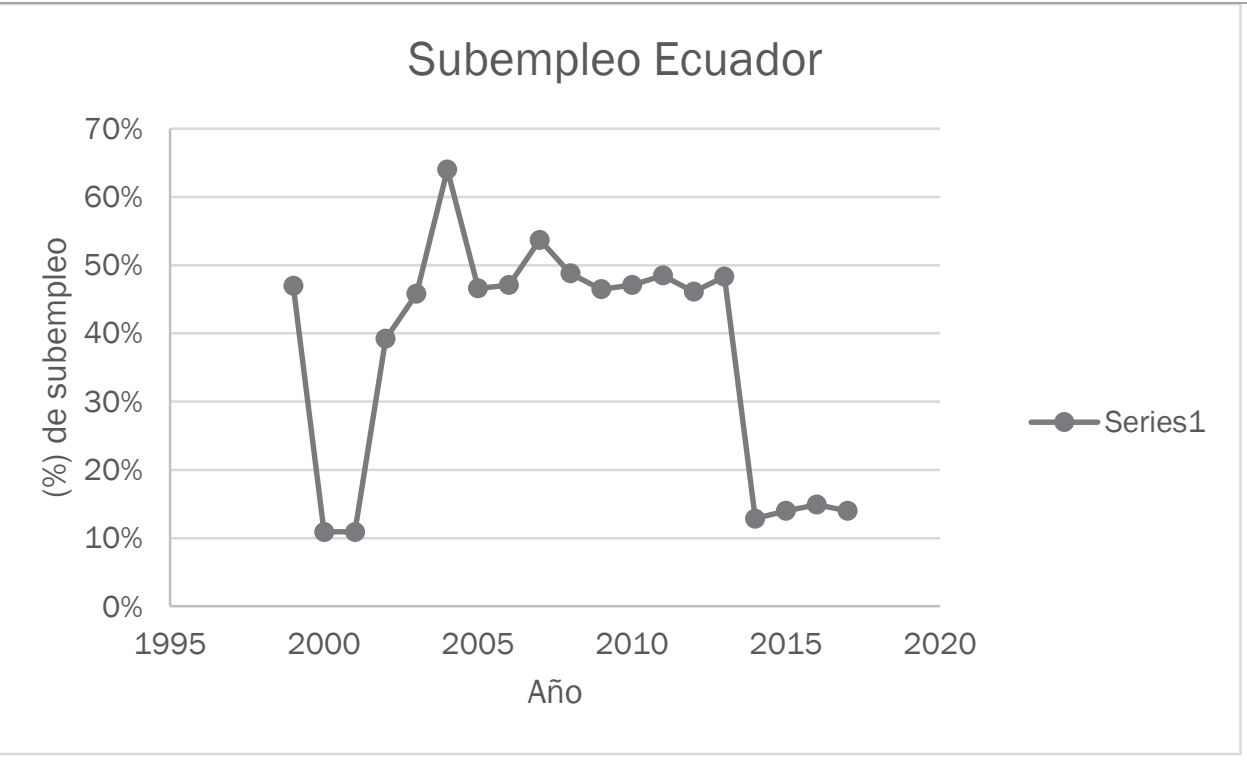

Gráfico 6 Tasa de subempleo en el Ecuador de 1999 al 2017

Fuente: Banco Central del Ecuador (2017)

Elaborado por: Los Autores

En la economía ecuatoriana, tanto el desempleo como el subempleo son problemas estructurales que no han sido remediados y se han mantenido a lo largo de su historia.

Según los datos del Banco Central del Ecuador y tomando como referencia el periodo 1992 a 1999 la tasa promedio de desempleo fue del 9.6\%: mientras que entre el 2000 y 2009 la misma decreció tan sólo en $0.5 \%$. Un factor relevante a considerar es la crisis de 1999 con la tasa más alta registrada de 14.4\% que contrasta con la cifra del año 2014 que registró el descenso más significativo del periodo de estudio con un valor equivalente a 3.80\%. A partir del año 2010 se evidencia un decrecimiento continuo del indicador hasta el año 2015 donde nuevamente se 


\section{Crisis económica política y social del Ecuador periodo 1998 hasta parte del primer semestre del 2018}

Vol. 3, núm. 1., (2019)

Jorge Aníbal Guilcaso Romero; José David Ronquillo Cando; Raúl Humberto Montaluisa

Pulloquinga

registra una tasa de $4.80 \%$ un punto porcentual más que en el año anterior. Finalmente en el año 2017 el índice de desempleo es el 4.6\%, con relación al año anterior, disminuyendo un $0.5 \%$, en los últimos 19 años analizados, los índices de desempleo han decrecido a partir del año 2001 luego de que la crisis financiera mundial también deje su impacto en el Ecuador. Junto con estas cifras del desempleo, es importante analizar el comportamiento del subempleo entendido como el empleo inadecuado relativo a la duración y a la productividad del trabajo en relación con una situación de empleo alternativo que la persona es capaz de desempeñar (Banco Central del Ecuador).

"EI desempleo y subempleo son variables que dependen básicamente del ritmo de crecimiento económico, del nivel y de la estructura de la inversión y del consumo de los agentes económicos de una nación.” (Rubén Holguín Arias, 2003, p.105)

El desempleo subió en el Ecuador del 38,5\% en marzo del 2017 al 41,1\% en marzo de 2018, de acuerdo con la Encuesta Nacional de Empleo, Desempleo y Subempleo, que publicó el Instituto Nacional de Estadística y Censos (INEC), este lunes 16 de abril de 2018. Es decir, la cantidad de habitantes del Ecuador que tiene empleo adecuado pasó de 3112953 personas a 3 356 562, al analizar este período. Asimismo, la cantidad de habitantes en situación de desempleo se incrementó de 355414 a 362051 personas, entre marzo del 2017 y marzo 2018. Por el contrario, el número de subempleados disminuyó de 1726030 a 1498139.

Variación del precio del petrolero 
Crisis económica política y social del Ecuador periodo 1998 hasta parte del primer semestre del 2018

Vol. 3, núm. 1., (2019)

Jorge Aníbal Guilcaso Romero; José David Ronquillo Cando; Raúl Humberto Montaluisa Pulloquinga

En el año 2000, Ecuador se encontraba sumido en la mayor crisis financiera de su historia, el precio del petróleo se redujo en $40 \%$, al pasar de \$15/barril promedio en 1997 a \$9/barril en 1998. Llegándose a cotizar por debajo de \$7/barril en ese año, y promediando \$15/barril en 1999. La caída del precio del petróleo duró 12 meses.

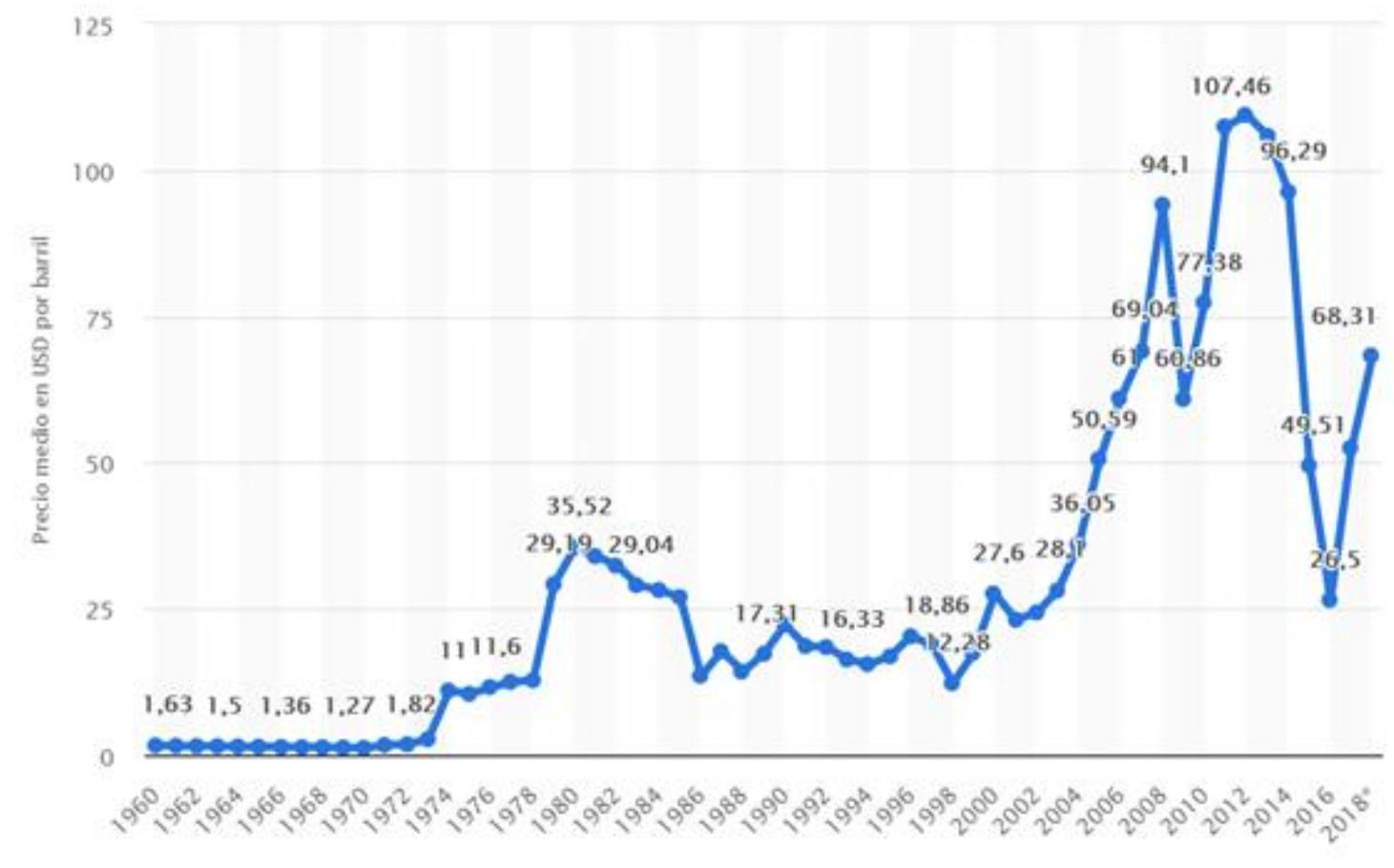




\section{Crisis económica política y social del Ecuador periodo 1998 hasta parte del}

primer semestre del 2018

Vol. 3, núm. 1., (2019)

Jorge Aníbal Guilcaso Romero; José David Ronquillo Cando; Raúl Humberto Montaluisa

Pulloquinga

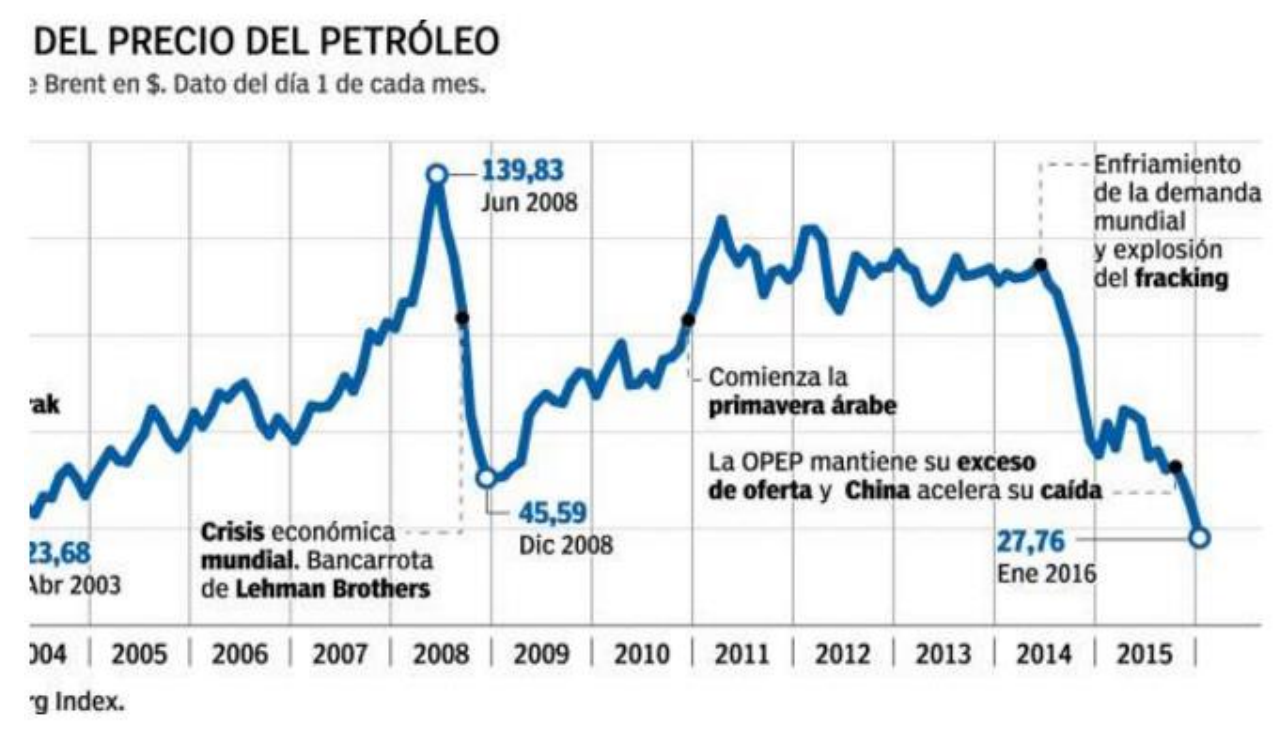

\section{Gráfico 7 Variación del petróleo en el Ecuador}

Fuente: Banco Central del Ecuador (2017)

Elaborado por: Los Autores

Con los datos recolectados del petróleo se pudo ver que el gobierno anterior pre vendió el petróleo a los chinos y algunos países quedándose el país sin ingresos hasta el 2021. ocasionando un gran perjuicio al estado por el precio de preventa del barril de petróleo y por otro lado los intereses de usura que paga el estado a los chinos y otros países por los préstamos como lo podemos ver en los datos que se presentan en los apartados siguientes:

Compromete una producción de aproximadamente 181 millones de barriles por ocho años con dos años de gracia. Lo anterior significa que el crudo comprometido se despachará desde el 2018 hasta el 2024. Se trata del mayor volumen comprometido en un contrato de compra y venta 
Crisis económica política y social del Ecuador periodo 1998 hasta parte del primer semestre del 2018

Vol. 3, núm. 1., (2019)

Jorge Aníbal Guilcaso Romero; José David Ronquillo Cando; Raúl Humberto Montaluisa Pulloquinga

de crudo con Petrochina, de los datos difundidos por Petroecuador, desde que comenzaron estas operaciones en el 2009.

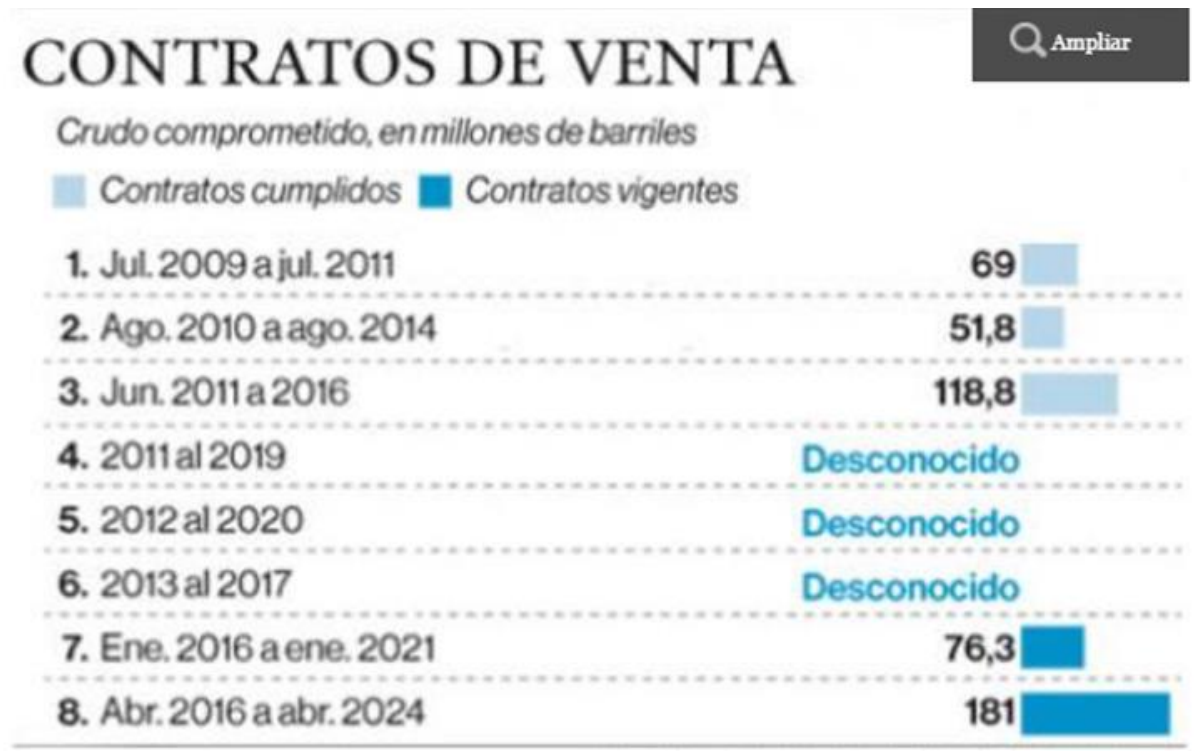

\section{Gráfico 8 preventa del petróleo de Ecuador a Petrochina}

Fuente: el Comercio (2017)

Elaborado por: Los Autores

Y no es el único acuerdo de compra y venta de crudo firmado este año entre ambas petroleras. En enero pasado se firmó otro contrato similar, a cinco años, que vencerá en el 2021. Con este acuerdo se comprometió la venta de 76,3 millones de barriles de crudo, según reveló este Diario en marzo pasado, tras una consulta efectuada a Petroecuador. Los dos contratos suscritos este año comprometen 257,3 millones de barriles, lo que equivale a más de un año y medio del volumen total exportado por Ecuador en el 2015, según datos del Banco Central. El 


\section{Crisis económica política y social del Ecuador periodo 1998 hasta parte del primer semestre del 2018}

Vol. 3, núm. 1., (2019)

Jorge Aníbal Guilcaso Romero; José David Ronquillo Cando; Raúl Humberto Montaluisa Pulloquinga

volumen equivale a más de seis años de procesamiento de crudo en la Refinería de Esmeraldas a plena capacidad: 110000 barriles diarios.

Análisis de la crisis económica, política y social en el Ecuador desde 1998 al 2017

Dr. Jamil Mahuad Witt: Período Presidencial: 11 de feb. De 1997 al 10 de ago. de 1998

El Ecuador en el año 1999 atravesó la mayor crisis económica de la historia, uno de los principales problemas que originó la banca privada, fue incurrir en el denominado riesgo moral, se puso en peligro todo un sistema financiero por las malas prácticas administrativas y de supervisión que permitían incurrir en negocios, que con mucha facilidad eran propensos a generar pérdidas en las instituciones bancarias. Para entender cuáles fueron los alcances de incurrir en el riesgo moral, es necesario conocer las principales causas y agentes que permitieron la debacle; entre ellos tenemos: La Crisis Asiática, El fenómeno del niño y la caída del precio del petróleo (Sacoto, 2015).

En el periodo de la causa de esta pésima administración, alineada con las políticas financieras y económicas dejaron una brecha enorme, los efectos causados por esta, provocaron el cierre de bancos, serios problemas de liquidez, falta de solvencia en el sistema financiero del País, y la intervención del Estado.

Dr. Gustavo Noboa Bejarano: Período Presidencial: 10 de ago. De 1998 al 21 de ene. de 2000

Los primeros meses de su gobierno fueron muy difíciles, pues el país atravesaba la peor crisis económica de los últimos cincuenta años de vida republicana, y el descontento popular - 


\section{Crisis económica política y social del Ecuador periodo 1998 hasta parte del primer semestre del 2018}

Vol. 3, núm. 1., (2019)

Jorge Aníbal Guilcaso Romero; José David Ronquillo Cando; Raúl Humberto Montaluisa Pulloquinga

sometido a tremenda presión- parecía una bomba a punto de estallar. Al congelamiento de dinero que el pueblo había sido sometido por el gobierno de Mahuad se sumaron la escasez de fuentes de trabajo y una serie exigencias económicas por parte de determinados gremios como los de los transportistas, los educadores y los trabajadores de la salud, que aprovecharon la ocasión para como es su costumbre- anunciar una serie de huelgas y paros que una vez más pusieron al país al borde del caos (Avilés, 2008).

El gobierno de Gustavo Noboa mantuvo el sistema de dolarización y acentuó las políticas neoliberales de derecha iniciadas por su antecesor. Realizó promesas de justicia social y de persistencia en la lucha contra la corrupción. Inicio diálogos con la CONAIE con el fin de apaciguar tensiones sociales por lo que dirigió una petición de amnistía para los civiles y militares que participaron en la asonada golpista, a lo que los legisladores respondieron de manera positiva. En enero del 2001 se produjeron manifestaciones de los estudiantes en Quito, Guayaquil y Cuenca, en contra al aumento de tarifas en el transporte público, precios de gas y combustibles (Gaibor, 2015). En febrero, Noboa decreto Estado de Emergencia, debido a un levantamiento indígena. Finalmente se llegó a un acuerdo, a cambio de una rectificación parcial del Gobierno en las recientes subidas de las tarifas de los combustibles, el gas doméstico y el transporte público.

Ing. Lucio Gutiérrez Borbua: Período Presidencial: 22 de ene. De 2000 al 15 de ene. de 2003

Según Correa (2003), El problema de la política económica del presidente Gutiérrez no es de ausencia de margen de acción, deliberadamente se trata de consolidar un modelo de desarrollo 


\section{Crisis económica política y social del Ecuador periodo 1998 hasta parte del primer semestre del 2018}

Vol. 3, núm. 1., (2019)

Jorge Aníbal Guilcaso Romero; José David Ronquillo Cando; Raúl Humberto Montaluisa Pulloquinga

ya en crisis en el resto del mundo, rechazado abrumadoramente en las urnas, y que ha sido un fracaso en cuanto a eficiencia y equidad en América Latina.

La política económica del actual régimen no tiene nada nuevo. Por el contrario, es la más ortodoxa expresión del pensamiento dominante en Latinoamérica. Trata de consolidar un modelo de desarrollo ya en crisis en el mundo, rechazado abrumadoramente en las urnas y que ha sido un fracaso en cuanto a eficiencia y equidad.

Dr. Alfredo Palacio: Período Presidencial: 15 de ene. De 2003 al 20 de abril de 2005

Según García (2016), durante el periodo 2005-2007, la economía nacional tuvo un incremento económico bastante pobre. Sectores como el comercio y en particular la agricultura creció apenas con una tasa de $1.9 \%$ tuvo en el IVA en la parte impositiva su principal fuente de ingresos seguido por las importaciones petroleras y por el impuesto causado a la renta y por el lado de los egresos aquel rubro fue al pago del servicio de la deuda que tuvo un egreso de casi un 45\% como segundo rubro de egresos fue el de servicios generales con la educación y cultura como sus principales pero la parte más importante de este gobierno fue la gran cantidad de recursos provenientes del petróleo que se dedicaron a cancelar deudas y obligaciones de gobiernos anteriores y no para generar actividades propias que generen utilidades en materia de educación y salud.

La inversión social por habitante subió de \$136 a \$ 155. Se incrementó la relación gasto social/PIB, al pasar del 5\% al 5,3\%: unos \$285 millones adicionales. 


\section{Crisis económica política y social del Ecuador periodo 1998 hasta parte del primer semestre del 2018 \\ Vol. 3, núm. 1., (2019) \\ Jorge Aníbal Guilcaso Romero; José David Ronquillo Cando; Raúl Humberto Montaluisa Pulloquinga}

Eco. Rafael Correa Delgado: Período Presidencial: 20 de abril de 2005 - 15 de enero de 2017

Desde fines del año pasado, ocho años de administración de la bonanza parecían sucumbir precipitadamente ante la obligada gestión de la austeridad. Esta vez toda hace pensar que la crisis económica no será como la de 2009, cuando un problemático semestre siguió a dos años de esplendoroso desafío a cualquier sombra de disciplina fiscal. Inmediatamente vino la recuperación. En ese entonces todavía quedaban reservas monetarias provenientes de los ahorros obligados por la ortodoxia neoliberal. A pesar de ambas cosas tanto de las reservas remanentes como de la corta duración de la crisis, el año 2009 se recuerda aún como el período de más baja popularidad en ocho años de gobierno: la valoración positiva de la gestión gubernamental llegó a casi el 50\% de aprobación cuando el promedio en años posteriores ha superado el $70 \%$.

Esta vez las cosas se presentan más peliagudas. No hay reservas internas disponibles y aunque la duración de la crisis es incierta podría prolongarse varios años. Se combinan una revaloración del dólar, una contracción del crédito internacional y una caída del precio de las materias primas que constituyen la base de las exportaciones ecuatorianas. La combinación de la apreciación de la moneda con la caída de las exportaciones petroleras presiona sobre dos déficits, el de la balanza comercial y el fiscal. El déficit fiscal a su vez impacta en dos de los factores centrales del crecimiento de los últimos años: el gasto público y el alto dinamismo del sector de la construcción. El anillo de la crisis se cierra con una previsible desmejora en la recaudación de 


\section{Crisis económica política y social del Ecuador periodo 1998 hasta parte del primer semestre del 2018}

Vol. 3, núm. 1., (2019)

Jorge Aníbal Guilcaso Romero; José David Ronquillo Cando; Raúl Humberto Montaluisa Pulloquinga

impuestos por la caída general de ingresos y actividades económicas. El tenor de las sombras que se ciernen sobre la gestión gubernamental y el país dependerá, por supuesto, de la profundidad y duración de la recesión global.

Por el momento, las cifras de la crisis fiscal son pavorosas. Los ingresos petroleros en el presupuesto del Estado cayeron de 6 mil millones en 2013 a un poco más de 2 mil millones en 2014 y a partir de 2015 los precios cayeron a la mitad del valor promedio de 2014, por lo que la situación empeorará. Si en 2012 cinco meses cerraron con déficit de caja en el Banco Central, en 2013 fueron ocho y en 2014 once meses. El déficit global que tuvo que ser financiado con deuda externa e interna en 2013 superó los 4 mil millones de dólares, el de 2014 los 7 mil y el déficit con que fue aprobada la proforma presupuestaria de 2015 fue de 8 mil 900 millones a pesar de presupuestarse sobre la base de un precio promedio del petróleo de 80 dólares el barril. Un cálculo conservador de las necesidades de financiación para 2015, basado en un modelamiento de sus impactos en venta de crudo y compra de derivados, supone que será de alrededor del $12 \%$ del PIB si el precio del crudo se mantiene en 50 US\$ el barril durante todo el año.

Las cifras de la crisis de balanza comercial son igualmente preocupantes. Desde el año 2009 el Ecuador tiene déficit en la balanza comercial a pesar de los altos precios del petróleo. No obstante en 2013 el déficit de la balanza comercial no petrolera llegó a superar los 9 mil millones de dólares. En 2014 se redujo a 7.600 millones gracias a un aumento de las exportaciones mineras y camaroneras y a una serie de restricciones a las importaciones. Ante la gravedad de la situación, el gobierno decidió imponer restricciones mucho más amplias a las importaciones. Esta vez, a diferencia de lo ocurrido en 2009, los órganos de la Comunidad Andina declararon 


\section{Crisis económica política y social del Ecuador periodo 1998 hasta parte del primer semestre del 2018}

Vol. 3, núm. 1., (2019)

Jorge Aníbal Guilcaso Romero; José David Ronquillo Cando; Raúl Humberto Montaluisa Pulloquinga

ilegales las salvaguardias iniciales impuestas por Ecuador a Colombia y Perú. Por ello se diseñó un sistema de salvaguardias generalizadas que durarán 15 meses a 2.800 partidas arancelarias que representan 8.500 millones de dólares en importaciones con el objetivo de reducir cuando menos 2.200 millones de bienes importados. Ante la imposibilidad de devaluar, las restricciones a las importaciones resultan inevitables, con su cortejo de presiones sobre la inflación. Puesto que son temporales, los sectores empresariales aspiran a que no entorpezcan el proceso de ratificación y puesta en vigor del Tratado de Libre Comercio con Europa al que Ecuador se adhirió recientemente, pero espera todavía su discusión en la Asamblea Nacional donde quizás se puedan conocer sus detalles, hasta ahora reservados. En todo caso, es previsible que la entrada en vigor de dicho tratado restrinja aún más el margen de maniobra del gobierno ante afectaciones externas y abaratará nuevas importaciones en un futuro próximo.

Mientras que la vicepresidenta de Ecuador, María Alejandra Vicuña Muñoz, aseguró hoy que en el Gobierno de Rafael Correa (2007-2017) "campeaba la corrupción" y dijo que el actual Ejecutivo no tolerará ni encubrirá este tipo de ilícitos.

Vicuña Muñoz (2017), dijo que el presidente Lenin Moreno -vicepresidente de Ecuador entre 2007 y 2013- recibió el Gobierno "de manos del expresidente Rafael Correa, en donde lamentable y dolorosamente la corrupción campeaba en los distintos sectores".

De forma que por más grande que sea la obra física construida, si detrás de ella está el sello inmoral de la corrupción jamás la defenderemos y mucho menos la encubriremos, como lamentablemente ocurriera en la última etapa del gobierno anterior del expresidente Correa. 


\section{Crisis económica política y social del Ecuador periodo 1998 hasta parte del}

primer semestre del 2018

Vol. 3, núm. 1., (2019)

Jorge Aníbal Guilcaso Romero; José David Ronquillo Cando; Raúl Humberto Montaluisa Pulloquinga

Un claro ejemplo del gobierno de Correa es la galopante corrupción como las estimaciones hechas por la comisión anticorrupción que indica que se robaron alrededor de 35000000 de dólares y los sobreprecios en todas las obras como por ejemplo lo reciente los complejos judiciales como el de Latacunga que de un monto de 1,9 millones estimado los costos, pagaron 7 millones y otros ejemplos más.

De forma que el gobierno de turno deberá crear las condiciones adecuadas para atraer la inversión tanto nacional como extranjera para dinamizar la economía y fomentar el empleo convirtiéndose en una necesidad la armoniosa relación que debe tener el estado y la parte privada como generadora de nuevos empleos pero sin descuidar sus deberes y responsabilidades frente a los trabajadores.

\section{Metodología.}

Esta investigación se realizó mediante la modalidad descriptiva y bibliográfica en donde se emplea una serie de herramientas y técnicas para la recolección de información de todos los aspectos y características de la realidad y así proporciona datos relevantes para describir y explicar los factores importantes.

El diseño de la investigación es la estrategia que adopta el investigador para responder al problema planteado, la presente investigación será cualitativa Según Sandoval (2002), considera a la investigación cualitativa, como "aquella que produce datos descriptivos: las propias palabras de las personas, habladas o escritas, y la conducta observable". También será cuantitativa porque 


\section{Crisis económica política y social del Ecuador periodo 1998 hasta parte del primer semestre del 2018}

Vol. 3, núm. 1., (2019)

Jorge Aníbal Guilcaso Romero; José David Ronquillo Cando; Raúl Humberto Montaluisa Pulloquinga

Pita \& Pértagas (2002), menciona que la investigación cuantitativa "es aquella en la que se recogen y analizan datos cuantitativos sobre variables" (p. 2).

Este tipo de investigaciones ayudaron en el estudio a realizar análisis estadístico de los resultados obtenidos, porque generará la comprensión del fenómeno y sus características y cuantitativa pues se considerarán términos económicos, políticos y sociales.

En el estudio también se utilizó investigación exploratoria, de manera que este tipo de investigación ayudo a familiarizarse con la situación problema, identifique las variables más importantes dentro del contexto teórico y práctico la misma que permite obtener datos y elementos precisos para la formulación de la hipótesis determinando con exactitud las causas que se originó para plantear la investigación.

También se utilizó la modalidad de investigación de campo porque permitió realizar el estudio en el lugar en que se producen los hechos. En esta modalidad el investigador toma contacto en forma directa con la realidad, para obtener información de acuerdo con los objetivos del proyecto (Herrera, Medina, \& Naranjo Galo, 2004). Por lo mismo se utilizó la investigación bibliográfica o documental, porque a través de la misma se pudo analizar la información escrita sobre el tema, con el propósito de establecer relaciones, diferencias, etapas, posturas o estado actual del conocimiento respecto al tema objeto de estudio, en cambio a través de la investigación documental se pudo recolectar información requerida de diferentes fuentes, bibliográficas, ya sean textos, periódicos, revistas, tesis, tesinas, artículos académicos, con la finalidad de explicar y ampliar la información acerca del tema objeto de estudio. 


\section{Crisis económica política y social del Ecuador periodo 1998 hasta parte del}

primer semestre del 2018

Vol. 3, núm. 1., (2019)

Jorge Aníbal Guilcaso Romero; José David Ronquillo Cando; Raúl Humberto Montaluisa

Pulloquinga

Para la recolección de información se realizó a través de un cuestionario pre elaborado.

Población y Muestra

Según datos del INEC (2010), para septiembre de 2017, la tasa nacional de desempleo fue de 4,1\% de la PEA, este indicador presentó una reducción estadísticamente significativa de 1,1 puntos porcentuales5 (p.p.), respecto al mismo periodo del año anterior (5,2\%). A nivel urbano la tasa fue de 5,4\%, esto representó una reducción significativa de 1,3 p.p. con respecto a septiembre de $2016(6,7 \%)$. A nivel rural la tasa de desempleo no presentó variaciones anuales significativas. Es decir la tasa de desempleo es mayor en la zona Urbana es por eso que se decide trabajar con personas de 20 a 44 años de la ciudad de Latacunga con el fin de recoger la información necesaria para el sustento del presente trabajo investigativo.

\section{Tabla 4 Población}

\begin{tabular}{|l|c|}
\hline RANGO DE EDADES & HABITANTES \\
\hline De 40 a 44 años & 20.405 \\
\hline De 35 a 39 años & 24.172 \\
\hline De 30 a 34 años & 27.117 \\
\hline De 25 a 29 años & 31.932 \\
\hline De 20 a 24 años & 35.680 \\
\hline TOTAL & $\mathbf{1 3 9 . 3 0 6}$ \\
\hline
\end{tabular}

Fuente: INEC (2010)

Elaborado por: Los Autores

Para la selección de la muestra se utilizó la siguiente formula estadística:

Entonces: 
Crisis económica política y social del Ecuador periodo 1998 hasta parte del primer semestre del 2018

Vol. 3, núm. 1., (2019)

Jorge Aníbal Guilcaso Romero; José David Ronquillo Cando; Raúl Humberto Montaluisa Pulloquinga

- $\quad$ e: (error de muestreo)

0.05

- N: (población)

139306 habitantes

- $\sigma:$ (probabilidad de ocurrencias y no ocurrencias)

0.5

- confianza

$95 \%$

- z: (Nivel de confianza)

- $\mathrm{n}$ :

$$
\begin{gathered}
n=\frac{N Z^{2} \sigma^{2}}{(\mathrm{~N}-1) e^{2}+\mathrm{Z}^{2} \sigma^{2}} \\
n=\frac{139306 * 1.96^{2} 0.5^{2}}{(139306-1) 0.05^{2}+1.96^{2} 0.5^{2}} \\
n=\frac{133.789 .48}{349.22} \\
\mathrm{n}=\text { (tamaño de la muestra) } 383 \text { personas }
\end{gathered}
$$

Por lo tanto, se puede indicar que el procesamiento de información se realizara a 383 personas a quienes se les aplicara la encuesta.

\section{Resultados.}

Análisis e interpretación de resultados

¿Considera que el país está atravesando una crisis económica, política y social?

Tabla 5 Atraviesa crisis económica 


\section{Crisis económica política y social del Ecuador periodo 1998 hasta parte del}

primer semestre del 2018

Vol. 3, núm. 1., (2019)

Jorge Aníbal Guilcaso Romero; José David Ronquillo Cando; Raúl Humberto Montaluisa

Pulloquinga

\begin{tabular}{|c|c|c|}
\hline ALTERNATIVA & FRECUENCIA & PORCENTAJE \\
\hline SI & 244 & $64 \%$ \\
\hline NO & 139 & $36 \%$ \\
\hline TOTAL & $\mathbf{3 8 3}$ & $\mathbf{1 0 0 \%}$ \\
\hline
\end{tabular}

Elaborado por: Los Autores

Fuente: Encuesta a ciudadanos

Gráfico 9 Atraviesa crisis económica

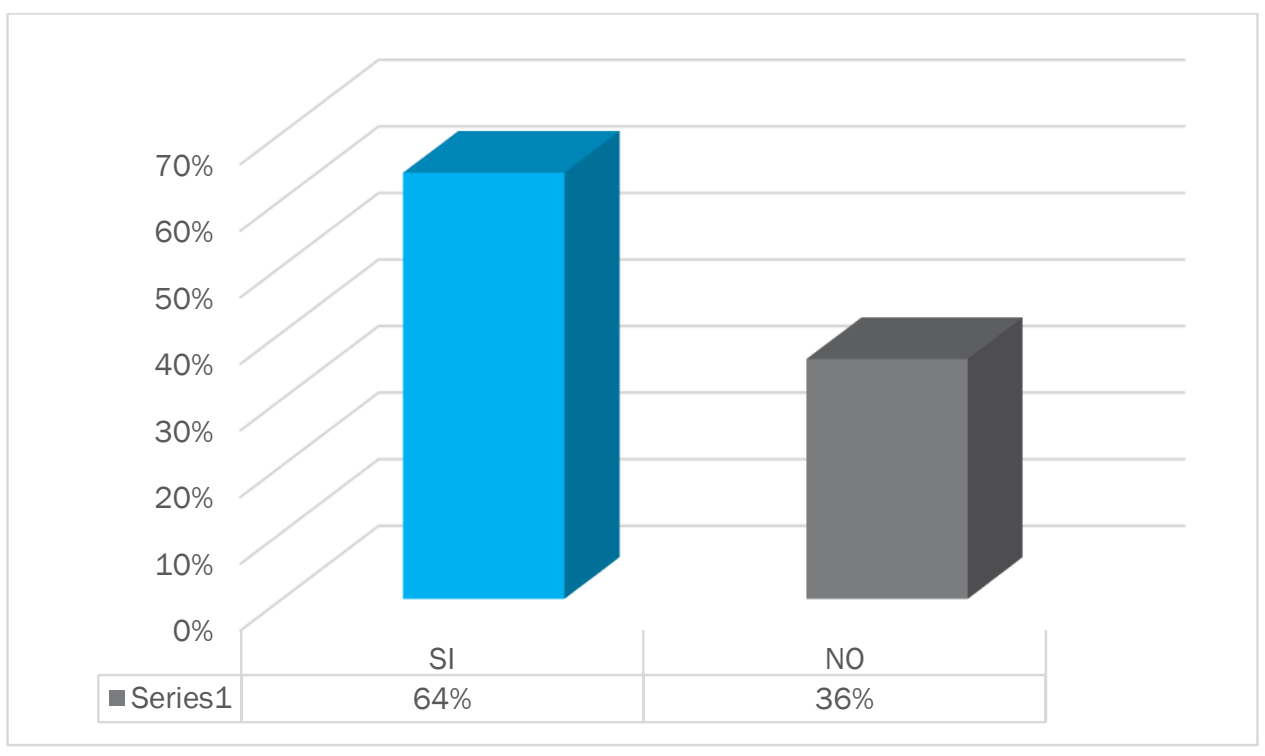

Elaborado por: Los Autores

Fuente: Encuesta a ciudadanos

Análisis e interpretación 
Crisis económica política y social del Ecuador periodo 1998 hasta parte del primer semestre del 2018

Vol. 3, núm. 1., (2019)

Jorge Aníbal Guilcaso Romero; José David Ronquillo Cando; Raúl Humberto Montaluisa Pulloquinga

El 64\% de encuestados mencionaron que consideran que el país está atravesando una crisis económica, política y social, mientras que el 36\% no considera que está atravesando una crisis, permitiendo conocer que el mayor número de ciudadanos conoce que el país está atravesando una fuerte crisis económica, política y social, ya que en el últimos años el aumento del desempleo, la incapacidad del Estado para financiar los servicios básicos, como salud y educación, el peso exorbitante de las deudas externa e interna, provocando que el país se encuentre vulnerable a cualquier crisis.

¿Considera que el feriado bancario producido en el año 2000 afecto a la economía del país?

Tabla 6 Feriado bancario afecta a la economía del país

\begin{tabular}{|c|c|c|}
\hline ALTERNATIVA & FRECUENCIA & PORCENTAJE \\
\hline SI & 265 & $69 \%$ \\
\hline NO & 118 & $31 \%$ \\
\hline TOTAL & $\mathbf{3 8 3}$ & $\mathbf{1 0 0 \%}$ \\
\hline
\end{tabular}

Elaborado por: Los Autores

Fuente: Encuesta a ciudadanos

\section{Gráfico 10 Feriado bancario afecta a la economía del país}




\section{Crisis económica política y social del Ecuador periodo 1998 hasta parte del}

primer semestre del 2018

Vol. 3, núm. 1., (2019)

Jorge Aníbal Guilcaso Romero; José David Ronquillo Cando; Raúl Humberto Montaluisa

Pulloquinga

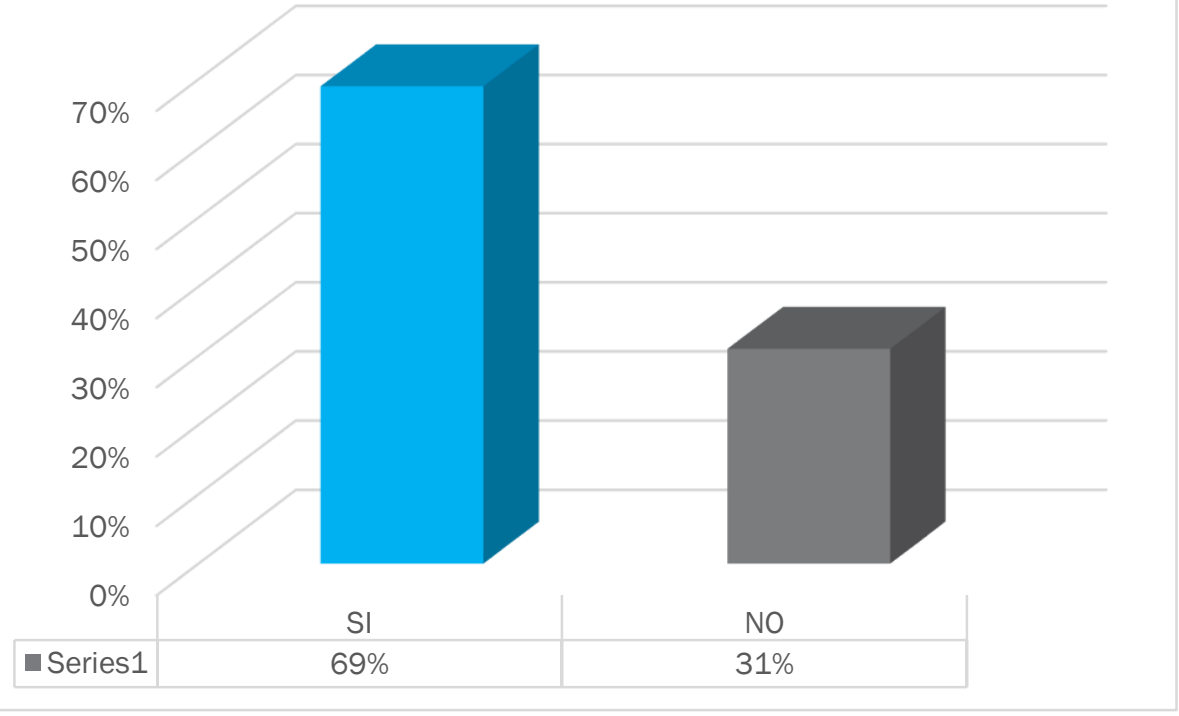

Elaborado por: Los Autores

Fuente: Encuesta a ciudadanos

Análisis e interpretación

El 69\% de los encuestados menciono que el feriado bancario producido en el año 2000 afecto a la economía del país, mientras que el $31 \%$ considero que no, dejando claro que el feriado bancario afecto considerablemente al país, ya que más del 50\% tuvieron que cerrar sus puertas, muchos ecuatorianos tuvieron que emigrar a otros países en busca de mejores oportunidades, Inflación, devaluación, recesión económica, y sobre todo lo que más afecto fue que el índice de pobreza, indigencia y desempleo creció, dejando al país en una crisis total.

¿Cuál de los siguientes factores considera que afecta de mayor manera a la crisis económica política y social que atraviesa el país? 
Crisis económica política y social del Ecuador periodo 1998 hasta parte del primer semestre del 2018

Vol. 3, núm. 1., (2019)

Jorge Aníbal Guilcaso Romero; José David Ronquillo Cando; Raúl Humberto Montaluisa Pulloquinga

Tabla 7 Factor que genera la crisis económica

\begin{tabular}{|l|c|c|}
\hline \multicolumn{1}{|c|}{ ALTERNATIVA } & FRECUENCIA & PORCENTAJE \\
\hline Mala administración del gobierno & 98 & $26 \%$ \\
\hline $\begin{array}{l}\text { Desembolso de dinero en gastos públicos } \\
\text { innecesarios }\end{array}$ & 185 & $48 \%$ \\
\hline Inflación & 60 & $16 \%$ \\
\hline Bajo precio del petróleo & 40 & $10 \%$ \\
\hline \multicolumn{1}{|c|}{ TOTAL } & $\mathbf{3 8 3}$ & $\mathbf{1 0 0 \%}$ \\
\hline
\end{tabular}

Elaborado por: Los Autores

Fuente: Encuesta a ciudadanos

\section{Gráfico 11 Factor que genera la crisis económica}

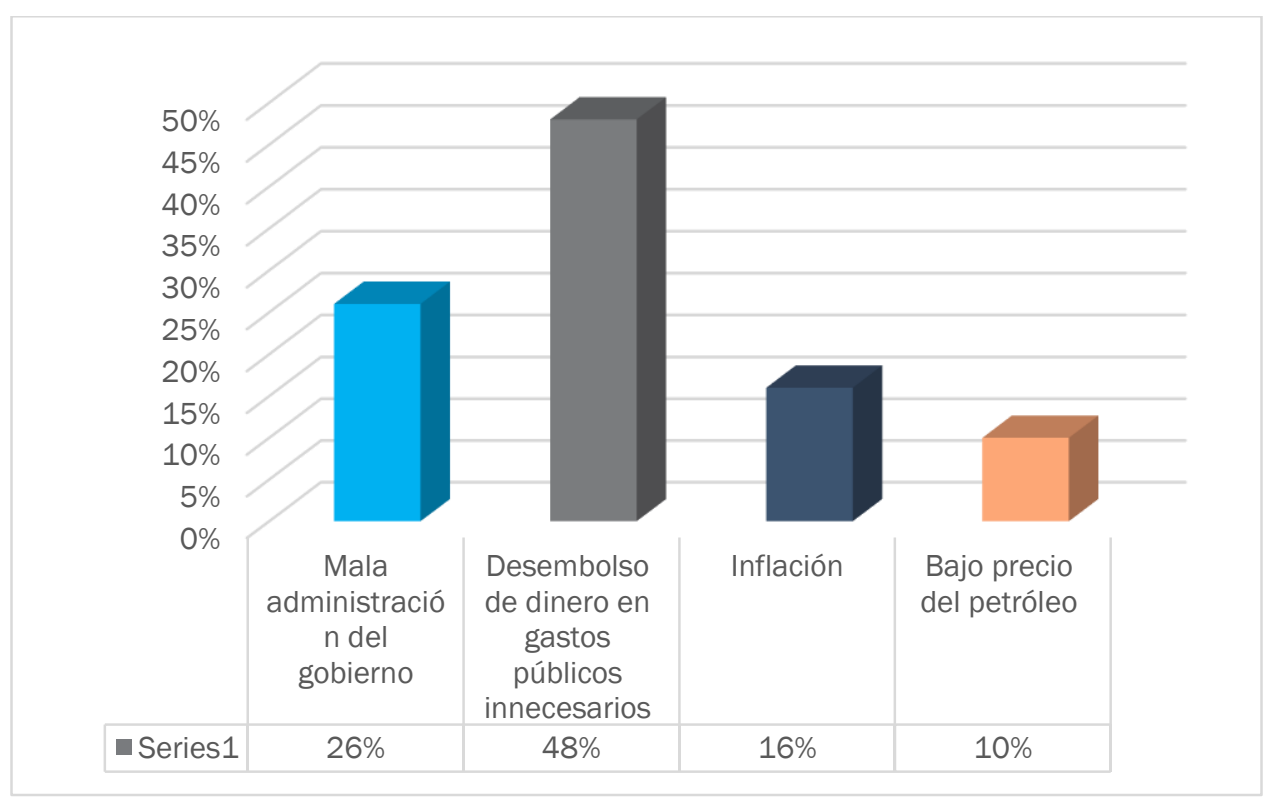




\section{Crisis económica política y social del Ecuador periodo 1998 hasta parte del}

primer semestre del 2018

Vol. 3, núm. 1., (2019)

Jorge Aníbal Guilcaso Romero; José David Ronquillo Cando; Raúl Humberto Montaluisa

Pulloquinga

\section{Elaborado por: Los Autores}

Fuente: Encuesta a ciudadanos

\section{Análisis e interpretación}

El 26\%, de los ciudadanos latacungueños indicaron que la mala administración del gobierno es el principal factor que ocasiona la crisis económica, política y social del país, el 16\% indica que la caída del precio del petróleo es un factor que afecta de mayor forma la crisis económica del país, el $48 \%$ indica que el factor es el desembolsos de dinero en gastos públicos innecesarios, finalmente el 16\% por la subida de la inflación, indicando que la administración del gobierno es uno de los factores principales en lo que respecta al correcto funcionamiento de un Estado ya que es gracias a las acciones que se realizan a través de estos organismos se pueden poner en práctica todas las decisiones que se toman.

¿Considera que la crisis económica del país afecta a las condiciones de vida de los ciudadanos del país?

Tabla 8 Crisis económica afecta a las condiciones de vida

\begin{tabular}{|c|c|c|}
\hline ALTERNATIVA & FRECUENCIA & PORCENTAJE \\
\hline SI & 285 & $74 \%$ \\
\hline NO & 98 & $26 \%$ \\
\hline TOTAL & $\mathbf{3 8 3}$ & $\mathbf{1 0 0 \%}$ \\
\hline
\end{tabular}

Elaborado por: Los Autores

Fuente: Encuesta a ciudadanos 
Crisis económica política y social del Ecuador periodo 1998 hasta parte del primer semestre del 2018

Vol. 3, núm. 1., (2019)

Jorge Aníbal Guilcaso Romero; José David Ronquillo Cando; Raúl Humberto Montaluisa Pulloquinga

\section{Gráfico 12 Crisis económica afecta a las condiciones de vida}

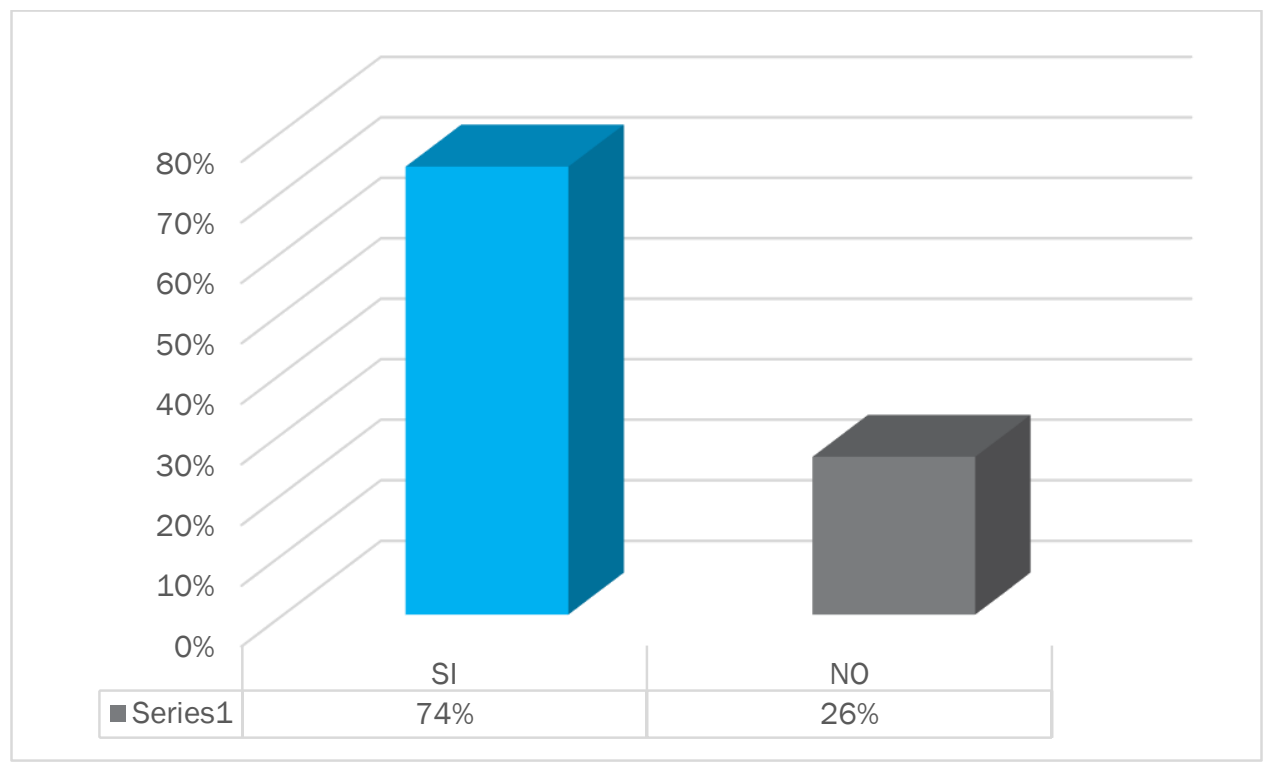

Elaborado por: Los Autores

Fuente: Encuesta a ciudadanos

\section{Análisis e interpretación}

El 74\% de ciudadanos mencionaron que la crisis económica, política, y social del país afecta las condiciones de vida de todos los ciudadanos ecuatorianos, mientras que el $26 \%$ menciono que no, dejando claro que la crisis económica, política y social afecta gravemente en el desarrollo de los ciudadanos, ya que es un desequilibrio que afecta, la educación, empleo, salud, vivienda entre otros.

¿Conoce el promedio inflacionario de países dolarizados? 
Crisis económica política y social del Ecuador periodo 1998 hasta parte del primer semestre del 2018

Vol. 3, núm. 1., (2019)

Jorge Aníbal Guilcaso Romero; José David Ronquillo Cando; Raúl Humberto Montaluisa

Pulloquinga

Tabla 9 Promedio de inflación de países dolarizados

\begin{tabular}{|c|c|c|}
\hline ALTERNATIVA & FRECUENCIA & PORCENTAJE \\
\hline SI & 70 & $18 \%$ \\
\hline NO & 313 & $82 \%$ \\
\hline TOTAL & $\mathbf{3 8 3}$ & $\mathbf{1 0 0 \%}$ \\
\hline
\end{tabular}

Elaborado por: Los Autores

Fuente: Encuesta a ciudadanos

Gráfico 13 Promedio de inflación de países dolarizados 
Crisis económica política y social del Ecuador periodo 1998 hasta parte del primer semestre del 2018

Vol. 3, núm. 1., (2019)

Jorge Aníbal Guilcaso Romero; José David Ronquillo Cando; Raúl Humberto Montaluisa Pulloquinga

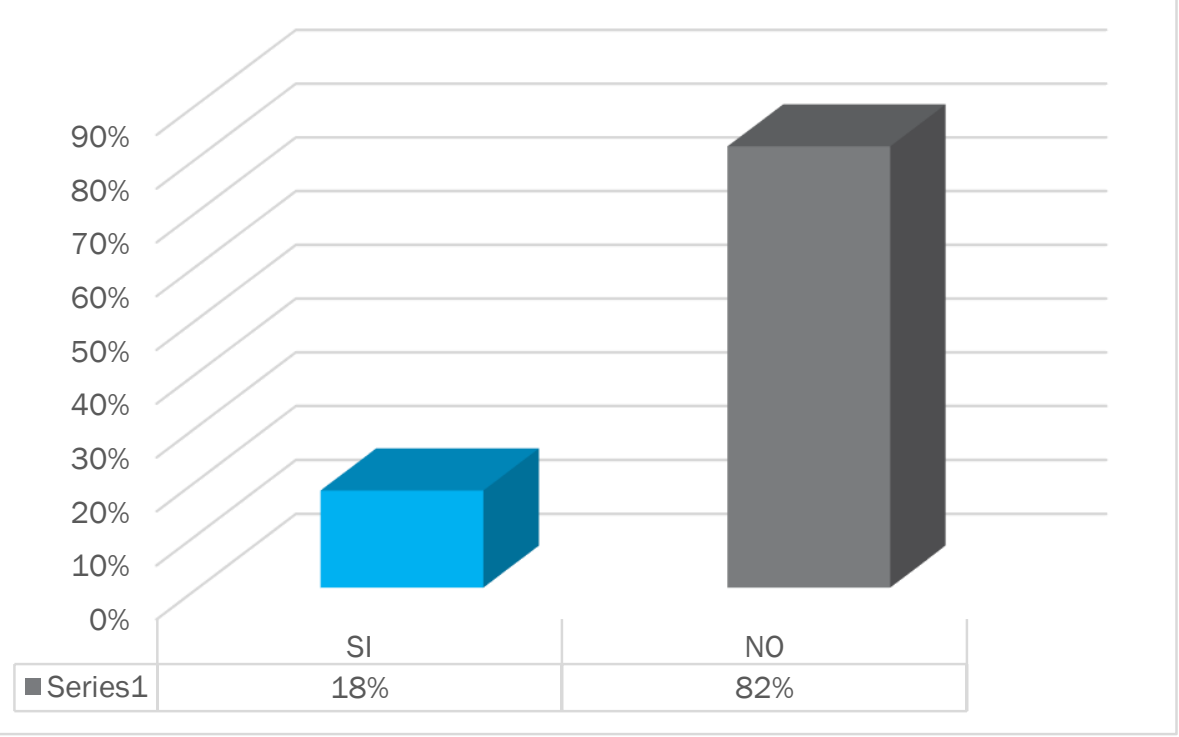

Elaborado por: Los Autores

Fuente: Encuesta a ciudadanos

Análisis e interpretación:

De las encuestas realizadas el $82 \%$ de la población latacungueña menciono que no conoce el promedio inflacionario de países dolarizados, mientras que el $18 \%$ menciono que sí, dejando conocer que más del 50\% está pendiente de la situación económica no solo del país sino de los países amigos. 


\section{Crisis económica política y social del Ecuador periodo 1998 hasta parte del}

primer semestre del 2018

Vol. 3, núm. 1., (2019) Jorge Aníbal Guilcaso Romero; José David Ronquillo Cando; Raúl Humberto Montaluisa Pulloquinga

¿Considera que los precios del petróleo afectan a la economía del país?

Tabla 10 Precios de petróleo afectan a la economía

\begin{tabular}{|c|c|c|}
\hline ALTERNATIVA & FRECUENCIA & PORCENTAJE \\
\hline SI & 350 & $91 \%$ \\
\hline NO & 33 & $9 \%$ \\
\hline TOTAL & $\mathbf{3 8 3}$ & $\mathbf{1 0 0 \%}$ \\
\hline
\end{tabular}

Elaborado por: Los Autores

Fuente: Encuesta a ciudadanos

\section{Gráfico 14 Precio de petróleo afecta a la economía}

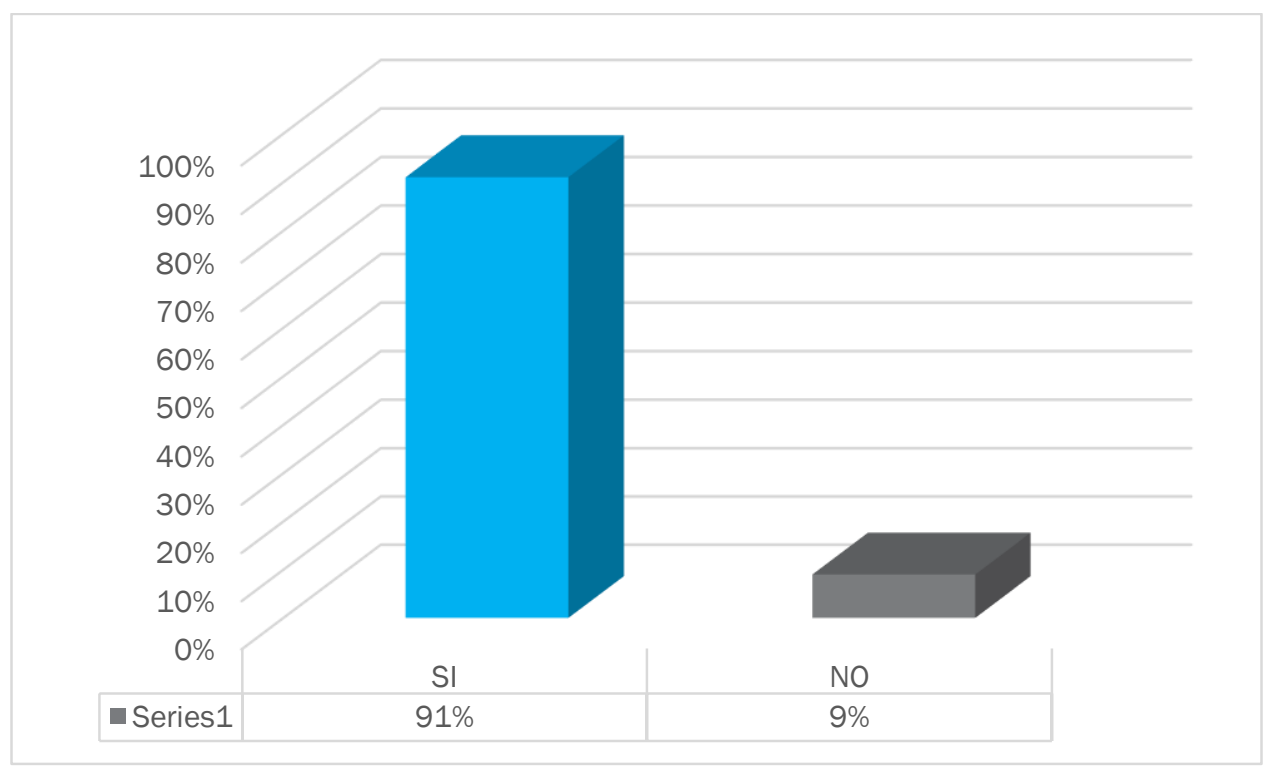

Elaborado por: Los Autores

Fuente: Encuesta a ciudadanos 
Crisis económica política y social del Ecuador periodo 1998 hasta parte del primer semestre del 2018

Vol. 3, núm. 1., (2019)

Jorge Aníbal Guilcaso Romero; José David Ronquillo Cando; Raúl Humberto Montaluisa Pulloquinga

Análisis e Interpretación:

El 91\% de encuestados menciono que los precios del petróleo afectan a la economía del país, mientras que el 9\% menciono que no, dejando claro que los precios del petróleo afectan a la economía del país, en gran forma, porque uno de los ingresos más grandes del país, además una buena parte de inversión pública se hace a partir de los ingresos y venta del petróleo, afectando también a la balanza comercial, de forma que fue más deficitaria por los bajos ingresos petroleros.

¿Tiene algún familiar fuera del país?

Tabla 11 Tiene algún familiar fuera del país

\begin{tabular}{|c|c|c|}
\hline ALTERNATIVA & FRECUENCIA & PORCENTAJE \\
\hline SI & 285 & $74 \%$ \\
\hline NO & 98 & $26 \%$ \\
\hline TOTAL & $\mathbf{3 8 3}$ & $\mathbf{1 0 0 \%}$ \\
\hline
\end{tabular}

Elaborado por: Los Autores

Fuente: Encuesta a ciudadanos 


\section{Crisis económica política y social del Ecuador periodo 1998 hasta parte del}

primer semestre del 2018

Vol. 3, núm. 1., (2019)

Jorge Aníbal Guilcaso Romero; José David Ronquillo Cando; Raúl Humberto Montaluisa

Pulloquinga

\section{Gráfico 15 Tiene algún familiar fuera del país}

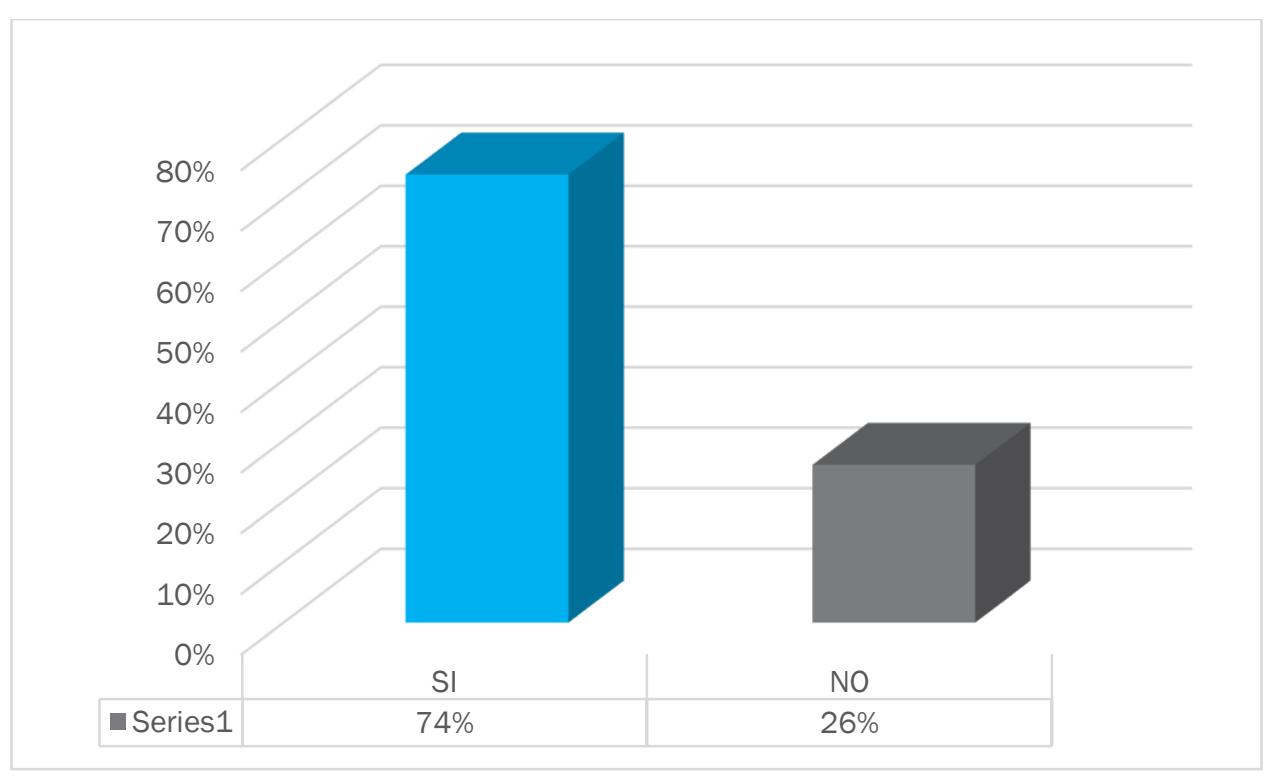

Elaborado por: Los Autores

Fuente: Encuesta a ciudadanos

\section{Análisis e Interpretación:}

El 74\% menciono que tiene algún familiar fuera del país, mientras que el 26\% dijo que no, dejando a la vista que por la fuerte crisis económica que atraviesa el país, los ciudadanos decidieron abandonar su familia, país, por buscar nuevas oportunidades en otros países. 
Crisis económica política y social del Ecuador periodo 1998 hasta parte del primer semestre del 2018

Vol. 3, núm. 1., (2019)

Jorge Aníbal Guilcaso Romero; José David Ronquillo Cando; Raúl Humberto Montaluisa Pulloquinga

¿Porque motivo tuvo que emigrar su familiar al exterior?

Tabla 12 Motivo de migración

\begin{tabular}{|l|c|c|}
\hline \multicolumn{1}{|c|}{ ALTERNATIVA } & FRECUENCIA & PORCENTAJE \\
\hline Causas económicas & 208 & $54 \%$ \\
\hline Causas familiares & 108 & $29 \%$ \\
\hline Causas sociales & 67 & $17 \%$ \\
\hline \multicolumn{1}{|c|}{ TOTAL } & $\mathbf{3 8 3}$ & $\mathbf{1 0 0 \%}$ \\
\hline
\end{tabular}

Elaborado por: Los Autores

Fuente: Encuesta a ciudadanos

Gráfico 16 Motivo de migración

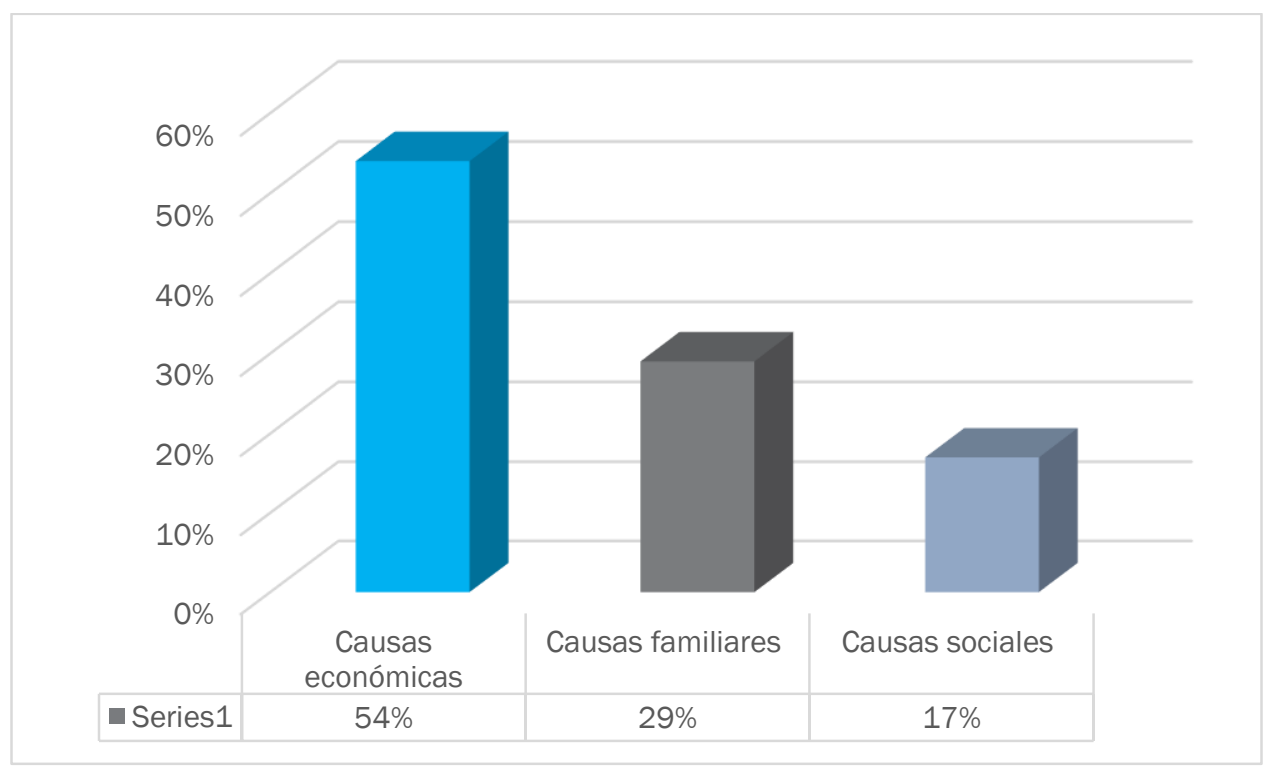

Elaborado por: Los Autores 


\section{Crisis económica política y social del Ecuador periodo 1998 hasta parte del}

primer semestre del 2018

Vol. 3, núm. 1., (2019)

Jorge Aníbal Guilcaso Romero; José David Ronquillo Cando; Raúl Humberto Montaluisa

Pulloquinga

Fuente: Encuesta a ciudadanos

\section{Análisis e Interpretación:}

El $54 \%$ de personas encuestadas menciono tuvo que emigrar al exterior por motivo económico, el 29\% por causas familiares, y el 17\% por causas sociales. Dejando claro que el mayor número de encuestados tuvo que emigrar por causas económicas, ya que con la actual administración los ciudadanos no cuentan con buenas oportunidades.

¿Tiene algún familiar desempleado?

\section{Tabla 13 Familiar desempleado}

\begin{tabular}{|c|c|c|}
\hline ALTERNATIVA & FRECUENCIA & PORCENTAJE \\
\hline SI & 300 & $78 \%$ \\
\hline NO & 83 & $22 \%$ \\
\hline TOTAL & $\mathbf{3 8 3}$ & $\mathbf{1 0 0 \%}$ \\
\hline
\end{tabular}

Elaborado por: Los Autores

Fuente: Encuesta a ciudadanos 
Crisis económica política y social del Ecuador periodo 1998 hasta parte del primer semestre del 2018

Vol. 3, núm. 1., (2019)

Jorge Aníbal Guilcaso Romero; José David Ronquillo Cando; Raúl Humberto Montaluisa Pulloquinga

\section{Gráfico 17 Familiar desempleado}

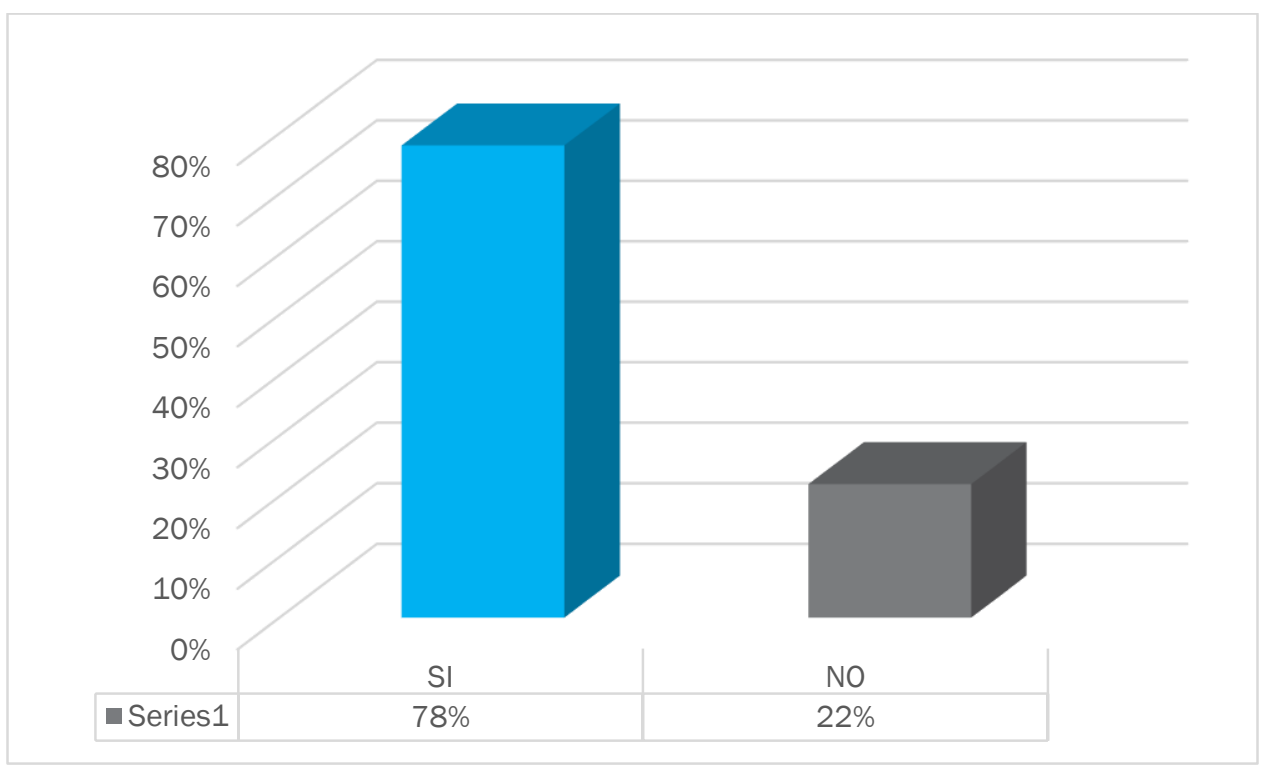

Elaborado por: Los Autores

Fuente: Encuesta a ciudadanos

Análisis e Interpretación:

El $78 \%$ de los encuestados menciono que tiene algún familiar desempleado, el $22 \%$ menciono que no, indicando que, por la política neoliberal históricamente adoptada por los gobiernos, constituye una causa primordial por la que se ha perpetuado el desempleo, así como también es la alta dependencia de mano de obra y tecnología extranjera 


\section{Crisis económica política y social del Ecuador periodo 1998 hasta parte del}

primer semestre del 2018

Vol. 3, núm. 1., (2019)

Jorge Aníbal Guilcaso Romero; José David Ronquillo Cando; Raúl Humberto Montaluisa

Pulloquinga

¿En qué gobierno considera que el país tuvo mayor crisis económica, política y social?

Tabla 14 Gobierno con mayor crisis económica

\begin{tabular}{|l|c|c|}
\hline \multicolumn{1}{|c|}{ ALTERNATIVA } & FRECUENCIA & PORCENTAJE \\
\hline Rafael Correa & 151 & $39 \%$ \\
\hline Jamil Mahuad & 149 & $39 \%$ \\
\hline Lucio Gutiérrez & 83 & $22 \%$ \\
\hline TOTAL & $\mathbf{3 8 3}$ & $\mathbf{1 0 0 \%}$ \\
\hline
\end{tabular}

Elaborado por: Los Autores

Fuente: Encuesta a ciudadanos

Gráfico 18 Gobierno con mayor crisis económica 
Crisis económica política y social del Ecuador periodo 1998 hasta parte del primer semestre del 2018

Vol. 3, núm. 1., (2019)

Jorge Aníbal Guilcaso Romero; José David Ronquillo Cando; Raúl Humberto Montaluisa Pulloquinga

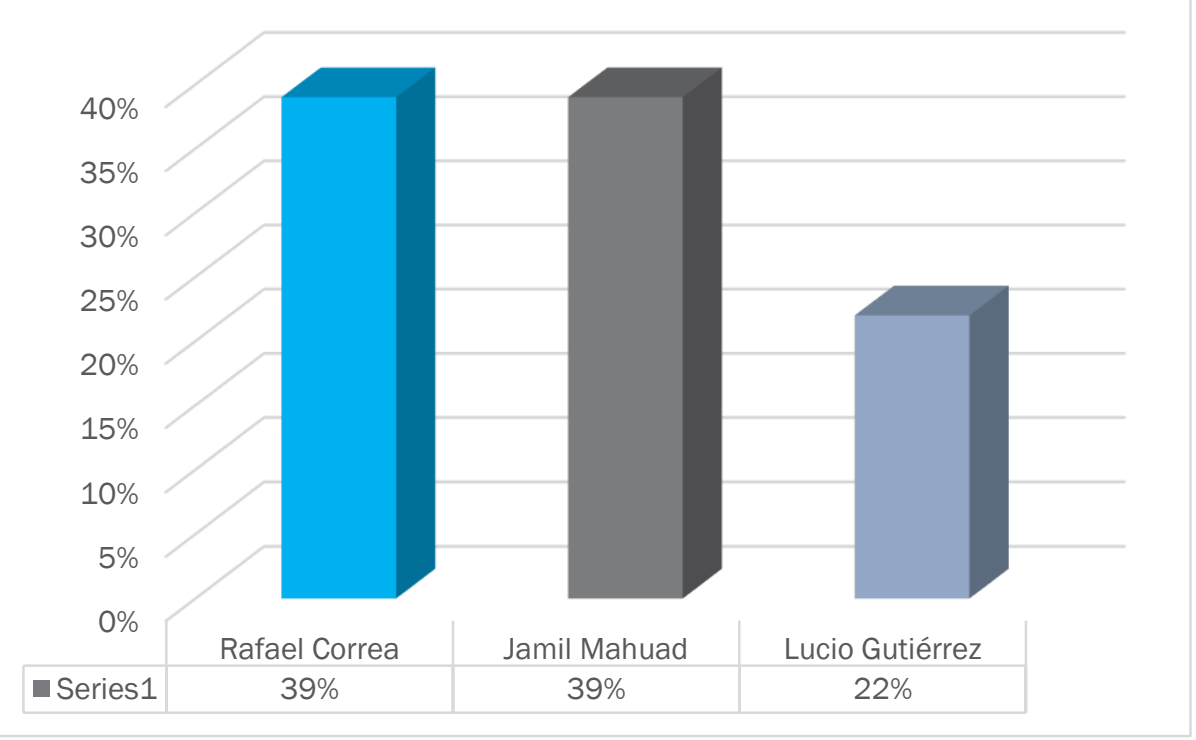

Elaborado por: Los Autores

Fuente: Encuesta a ciudadanos

Análisis e interpretación:

El 39\% de encuestados latacungueños menciono que el gobierno considera que el país tuvo mayor crisis económica, política y social en el gobierno de Rafael Correa, el 39\% menciono que, en gobierno de Jamil Mahuad, y el 22\% menciono que en gobierno de Lucio Gutiérrez, determinando que la mayor crisis económica que ha sufrido el país han sido en los gobiernos de Rafael correa y Jamil Mahuad.

\section{Discusión.}

A través del estudio presentado se pudo determinar que el Ecuador está atravesando una crisis económica, política y social, con el $64 \%$, resaltando que se encuentra sumido en una de las 


\section{Crisis económica política y social del Ecuador periodo 1998 hasta parte del primer semestre del 2018}

Vol. 3, núm. 1., (2019)

Jorge Aníbal Guilcaso Romero; José David Ronquillo Cando; Raúl Humberto Montaluisa Pulloquinga

crisis más profundas de la posguerra. Las quiebras empresariales, el aumento del desempleo, la incapacidad del Estado para financiar los servicios básicos, como salud y educación, el peso exorbitante de las deudas externa e interna, la desconfianza en las instituciones financieras y en general en las instituciones existentes, la pérdida de poder adquisitivo de los hogares, el aumento del desempleo, de la pobreza y la delincuencia, las tensiones regionales, han alcanzado magnitudes no registradas en ningún otro momento en la posguerra como lo indica el estudio de (Salgado, 2016).

También se puede ver que el 69\% considera que el feriado bancario producido en el año 2000 afecto a la economía del país de gran forma, así como también lo menciona el estudio de (Cerdas , Jiménez, \& Valverde, 2000), En definitiva el país atravesaba una de las peores crisis económicas vividas en los todos los tiempos, con los indicadores macroeconómicos por los suelos, un descontento general en la población, desconfianza en el sistema financiero, recesión en el aparato productivo y aislamiento internacional. Estas razones obligaron al gobierno a actuar de inmediato, sin realizar un análisis profundo, entonces el presidente Jamil Mahuad puso en marcha un nuevo sistema monetario a la dolarización.

En cambio el estudio presenta que el $48 \%$ indica que el factor que afecta de mayor manera la crisis económica política y social del país son los desembolsos de dinero en gastos públicos innecesarios, afectando las condiciones de vida de los habitantes como lo indican los resultados con el 74\%, afectando en educación, empleo, salud, vivienda entre otros.

La caída de los precios del barril de petróleo provocó que la economía se vea contraída y que los problemas de la falta de ingresos afecten la Balanza de Pago y la Balanza Comercial como 
Crisis económica política y social del Ecuador periodo 1998 hasta parte del primer semestre del 2018

Vol. 3, núm. 1., (2019)

Jorge Aníbal Guilcaso Romero; José David Ronquillo Cando; Raúl Humberto Montaluisa Pulloquinga

indican los resultados con el 91\%, al igual que lo presenta el estudio de (Miranda , 2016), las razones de las drásticas bajas de los precios de barril de petróleo dejan de tener un carácter geopolítico, y se tomaría como factor importante a la tecnología y su búsqueda de dejar de depender de combustibles fósiles como lo es petróleo y a la vez se estaría ayudando a la reducción de la contaminación que afecta al planeta.

Se pudo conocer que el $74 \%$ de la población tiene un familiar fuera del país, dejando a la vista que por la fuerte crisis económica que atraviesa el país, los ciudadanos decidieron abandonar su familia, país, por buscar nuevas oportunidades en otros países, como también el 54\% tuvo que emigrar al exterior por motivo económico, porque el 78\% tiene algún familiar desempleado por la política neoliberal históricamente adoptada por los gobiernos, constituye una causa primordial por la que se ha perpetuado el desempleo, así como también es la alta dependencia de mano de obra y tecnología extranjera, manteniendo la idea que el 39\% de ciudadanos indico que el país tuvo mayor crisis económica, política y social, en el gobierno de Rafael Correa, y en de Jamil Mahuad.

\section{Conclusión.}

La Crisis Económica que ha experimentado nuestro país entre con el pasar del tiempo, ha venido deteriorando la calidad de vida de los ciudadanos ecuatorianos.

Se concluye que el ecuador a lo largo de su historia ha pasado por una crisis económica, política y social muy difícil, producida por varios factores; porque la inflación, desempleo, 


\section{Crisis económica política y social del Ecuador periodo 1998 hasta parte del primer semestre del 2018}

Vol. 3, núm. 1., (2019)

Jorge Aníbal Guilcaso Romero; José David Ronquillo Cando; Raúl Humberto Montaluisa Pulloquinga

endeudamiento externo han sufrido un incremento, produciendo un deteriorado progresivamente a la capacidad adquisitiva de los ecuatorianos.

\section{Bibliografía.}

Acosta, A. (1998). Reactivación y empleo . Quito .

Acosta , A., \& Serrano, A. (2016). Ecuador frente a la crisis económica internacional: un reto de multiples artistas. Quito.

Aguilera, F. (2015). El impacto de la crisis financiera y econ\{omica internacional de la banca del Ecuador (Primera ed., Vol. 178). Quito, Ecuador : Corporaci\{on Editora Nacional. Obtenido de http://repositorio.uasb.edu.ec/bitstream/10644/4690/1/SM178-AguileraEl\%20impacto.pdf

Álvarez , F. M. (2000). Crisis económica como causa de deterioro de la calidad de vida, periodo: 1988: 1998 sus perspectivas. Tesis doctoral, Instituto de Altos Estudios, Quito. Obtenido de http://repositorio.iaen.edu.ec/bitstream/24000/464/1/TESIS\%C3\%81LVAREZ\%20MARCO.pdf

Avilés, P. E. (2008). Enciclopedia del Ecuador . Obtenido de http://www.enciclopediadelecuador.com/personajes-historicos/dr-gustavo-noboa/

Cerdas , E., Jiménez , F., \& Valverde, M. (2000). Crsisis del Ecuador en el año 2000. Quito. Obtenido de http://www.memoriacrisisbancaria.com/www/articulos/Crisis_Ecuador_19992000_Aula_Economia.pdf

Cerdas, E., Jiménez , F., \& Valverde, M. (2006). Crisis del Ecuador en los años 1999 - 2000. Tesis doctoral , UMED, Quito. Obtenido de http://www.auladeeconomia.com/articulosot14.htm

Correa , R. (2003). La política económica del gobierno de Lucio Gutiérrez. Una perspectiva desde la economía política. Redalyc, 6. Obtenido de file:///D:/Usuario/Descargas/art\%C3\%ADculo_redalyc_50901601.pdf

Espinoza, R. (2005). La Crisis Económica Financiera Ecuatoriana de finales de siglo y la dolarización. Quito. Obtenido de http://www.uasb.edu.ec/padh/

Faria , H., \& Sabino , C. (1997). La Inflación . Ecuador . 


\section{Crisis económica política y social del Ecuador periodo 1998 hasta parte del primer semestre del 2018}

Vol. 3, núm. 1., (2019)

Jorge Aníbal Guilcaso Romero; José David Ronquillo Cando; Raúl Humberto Montaluisa Pulloquinga

Gaibor, M. (2015). Cambios culturales en el Ecuador. Obtenido de http://dorisgaibor.blogspot.com/2015/02/gobierno-de-gustavo-noboa-bejarano.html

García , R. J. (2016). Análisis económico del gasto público en el crecimiento económico del Ecuador 1965-2012. Universidad Católica de Santiago de Guayaquil , Guayaquil.

Herrera, L., Medina, A., \& Naranjo Galo. (2004). Tutoría de la Investigación Científica . Quito.

Index Mundi . (2018). Obtenido de https://www.indexmundi.com/g/g.aspx?c=ec\&v=71\&l=es

La Hora. (2018). Ecuador entre los paises mas caros . pág. 10.

Larrea, C., \& Sánchez, J. (2015). Dolarización y crisis en el Ecuador. Artículo academico , Quito . Obtenido de http://www.dlh.lahora.com.ec/paginas/debate/paginas/debate905.htm

León, M., Ponce , J., Troya , P., Velazco , M., \& Brborich, W. (2000). Ecuador: crisis y protección social. Sistema Integrado de Indicadores Sociales del Ecuador . Quito: Abya Yala.

Obtenido http://www.siise.gob.ec/siiseweb/PageWebs/RES/pubsii/pubsii_0044.pdf

Miranda , B. C. (2016). La caída del precio del petroleo y su incidencia en la economía ecuatoriana. Tesis doctoral, Universidad Católica de Santiago de Guayaquil , Facultad de Especialidades Empresariales , Guayaquil. Obtenido de http://repositorio.ucsg.edu.ec/bitstream/3317/5108/1/T-UCSG-PRE-ESP-CFI-210.pdf

Muñoz, L. P. (2006). Ecuador: Reforma del estado y y crisis política de 1992-2005. Artículo académico , Pontificia Universidad Católica del Ecuador, Quito. Obtenido de file:///D:/Usuario/Descargas/Dialnet-

EcuadorReformaDelEstadoYCrisisPolitica19922005-2380208.pdf

Pita, F., \& Pértagas, D. (2002). Investigaciòn cuantitativa y cualitativa. Unidad de Epidemiología Clínica y Bioestadística, ESpaña. Obtenido de https://www.fisterra.com/mbe/investiga/cuanti_cuali/cuanti_cuali2.pdf

Sacoto, F. R. (2015). Análisis de la crisis financiera en el Ecuador en el año 1999, con enfoque en el riego moral. Tesis doctoral, Guayaquil.

Salgado , W. (2016). Crisis económica en el Ecuador y los derechos económicos y sociales. Artículo Científico, Quito.

Salgado, W. (2016). La crisis económicas en el Ecuador y los derechos económicos sociales. Artículo , Quito. Obtenido de http://www.memoriacrisisbancaria.com/www/articulos/Wilma_Salgado_derechos_econo micos_y_sociales.pdf 


\section{Crisis económica política y social del Ecuador periodo 1998 hasta parte del}

primer semestre del 2018

Vol. 3, núm. 1., (2019)

Jorge Aníbal Guilcaso Romero; José David Ronquillo Cando; Raúl Humberto Montaluisa

Pulloquinga

Sandoval, C. C. (2002). Programa de especializacion en teoria mètodos y tècnicas de investigaciòn social. Instituto Colombiano para el Fomento de la Educacion Superior ICFES.

Bogota:

Arfo.

Obtenido

de https://panel.inkuba.com/sites/2/archivos/manual\%20colombia\%20cualitativo.pdf 